\title{
Creditor protection and the dynamics of the distribution in oligarchic societies
}

\author{
Manuel Oechslin
}

Published online: 19 November 2009

(C) The Author(s) 2009. This article is published with open access at Springerlink.com

\begin{abstract}
This paper analyzes the impact of weak contracting institutions on economic development and the wealth distribution in a Ramsey-type growth model. We show that, at low levels of accumulation, weak contracting institutions strongly favor the economic elite: By preventing market entry, such institutions provide the "oligarchs" with cheap access to credit - which is highly beneficial as long as capital is scarce. At the same time, a broad crosssection of society faces only low returns so that capital accumulation is slowed down and the capital stock gets concentrated in the hands of the elite. At higher levels of development, however, weak contracting institutions are harmful to all segments of society and institutional reform becomes unanimously supported. So the model helps to explain the pervasiveness of weak contracting institutions in less-advanced economies.
\end{abstract}

Keywords Contract enforcement - Wealth distribution · Economic development . Oligarchy

JEL Classification $\mathrm{O} 11 \cdot \mathrm{O} 43 \cdot \mathrm{D} 31$

\section{Introduction}

Many societies feature a significant divide in economic opportunities. Poor nations in particular tend to implement institutional arrangements which protect the established producers (i.e., the economic elite) from potential outside competitors. Such barriers to entry frequently

The author thanks Daron Acemoglu, Abhijit Banerjee, Giuseppe Bertola, Johannes Binswanger, Josef Falkinger, Ernst Fehr, Reto Föllmi, Oded Galor, Anke Gerber, Dirk Krueger, Torsten Persson, Klaus Reiner Schenk-Hoppé, Guido Tabellini, Harald Uhlig, Fabrizio Zilibotti, Josef Zweimüller, and seminar participants at Boston University, Brown University, the European Winter Meeting of the Econometric Society in Instanbul, the Federal Reserve Bank of Chicago, the German Macro Workshop in Würzburg, M.I.T., the University of Leicester, and the University of Zurich for helpful comments.

M. Oechslin $(\varangle)$

Department of Economics, Tilburg University, P.O. Box 90153, 5000 LE Tilburg, The Netherlands 
involve different but complementary elements: there is typically a "bad" contractual environment which renders access to the banking system difficult without sufficient collateral or long-standing business relations. At the same time, however, costly regulations of entry make access to credit crucial—and hence complicate market entry even further.

The pervasiveness of such economic institutions is widely recognized and there is now a growing consensus that they hamper economic performance. ${ }^{1}$ However, quite surprisingly, we know only little about their implications in standard models of economic growth. This paper contributes to the existing knowledge by introducing weak contract enforcement and prohibitive regulation of entry into a tractable Ramsey-type growth model where individuals make forward-looking savings and investment decisions and where the factor prices are endogenously determined. The purpose is to address two related sets of issues: first, we assess how this institutional environment (which we will call elite-protecting) affects longrun economic development, the dynamics of the wealth distribution, and the welfare of the different groups in society. Second, adopting a political-economy perspective, we look at the dynamics of the institutional environment as the economy develops over time.

We find the implications of elite-protecting institutions to vary largely with the level of economic development. At low levels of accumulation, such institutions lift the profits of the elite-run firms but, at the same time, depress the returns to accumulation for a broad cross-section of society. As a result, capital accumulation is slowed down and the dynamics of the wealth distribution are altered strongly in favor of the elite. Yet, at more advanced levels, the elite-protecting environment tends to become a burden for all segments of society so that, at a certain point, even the elite may support institutional reform. Thus, provided that the established producers hold political power, the model predicts less-advanced economies to adopt elite-protecting institutions-which, in turn, prevent the economy from advancing fast. On the other hand, consistent with the empirical picture, advanced economies tend to adopt strong contracting institutions (and to cut back on other entry barriers).

To see the driving force behind these results, consider the following society. There are two groups of individuals, the workers and the oligarchs (who constitute the elite). ${ }^{2}$ The workers are barred from entrepreneurship due to, for instance, costly licensing of new businesses. So as far as the workers save, they have to lend to the elite in order to earn a positive return. The credit market, however, is imperfect in the sense that the borrowers can only borrow up to a finite amount. The credit limit emerges endogenously because credit contracts are not well enforced. An important implication of these assumptions is that the equilibrium borrowing rate may lie below the marginal product of capital: a lower borrowing rate increases the oligarchs' borrowing capacity and hence allows them to absorb a certain credit supply by the workers. The latter, in turn, are prepared to lend at a low rate because of the lack of an alternative use for their savings. Hence, there is a spread between the workers' and the oligarchs' rate of return. While the workers experience a low return, the oligarchs-having access to cheap credit-face one that is higher than the marginal product of capital.

This price-manipulation effect dampens the equalizing forces present in a similar undistorted (first-best) economy and strongly alters the dynamics of the distribution in favor of the elite: with forward-looking savings decisions, low future returns reduce the workers' incentives to save; they discount prospective labor income less and hence perceive a high

\footnotetext{
${ }^{1}$ See Sect. 2.1 below for some empirical evidence on the institutional environment in less-developed or emerging economies. See, for instance, Engerman and Sokoloff (1997) for historical evidence on the impact of elite-protecting institutions on economic performance. See, among others, Hall and Jones (1999) and Acemoglu et al. (2001) for the empirical evidence.

${ }^{2}$ It is most natural to think of the workers as middle class agents who participate in the formal economy by supplying their skills in the labor market. They are called "workers" simply for brevity.
} 
"value" of the future income stream-which leads to a low propensity to save out of wages. ${ }^{3}$ The oligarchs find themselves in the opposite situation: they are induced to accumulate faster so that capital becomes highly concentrated in the hands of a tiny group. Yet, this surge in savings by the elite does not fully compensate for the workers' lower propensity to save; the net impact on aggregate savings is negative so that the pace of capital accumulation is slower. Besides the price-manipulation effect, this slowdown effect is the second channel through which the elite-protecting environment exerts a positive impact on the oligarchs' lifetime utility. While the conduciveness of the price-manipulation effect is obvious, the intuition behind the latter is more subtle: slower accumulation by the rest of society means a slower decline in the marginal product of capital — which must benefit the major capital owners.

However, alongside these beneficial implications, there are also possible negative consequences for the elite. In particular, weak contracting institutions may limit the extent to which the elite-run firms can purchase complementary factors of production in an international market; as a result, the marginal productivity of capital may be depressed. Interestingly, magnitude and direction of the net effect on the oligarchs' welfare crucially depend on the level of economic development: at low levels of accumulation, both the price-manipulation effect and the slowdown effect are strong so that the positive implications tend to dominate. However, with capital no longer "scarce" and concentrated in the hands of the elite, the positive effects weaken so that the net effect turns negative at some point. Put differently, the elite-protecting environment—by inducing the oligarchs to accumulate fast-influences the dynamics of the aggregate capital stock and its distribution in a way that makes the benefits disappear over time. This pattern is then reflected in the endogenous evolution of the institutional environment under elite rule: at early stages of development, oligarchic governments establish elite-protecting institutions while-at later stages - these regimes try to improve contract enforcement and hence the functioning of the financial system and related markets.

Additional properties of the model are highlighted in the numerical part of the paper (which also provides an intuition for the quantitative implications). We find, for instance, that the rents from the price-manipulation effect and the slowdown effect are consistently higher at lower levels of accumulation. An immediate conclusion is that (oligarchic) countries with particularly scarce capital endowments tend to implement elite-protecting institutions even if such institutions had a huge negative impact on productivity. Further interesting results concern institutional persistence. The simulations suggest that the elite-just to exploit the benefits from price-manipulation and slowdown-may preserve elite-protecting institutions for decades even if they impose a substantial cost in terms of lower productivity.

By identifying redistributive effects that are tied to the level of development, the present theory can accommodate recent cross-country evidence which regularly highlights the pervasiveness of weak contract enforcement (and complementary obstacles to entrepreneurship) in less-advanced economies. Moreover, the mechanisms and predictions described here are consistent with the well-examined historical experiences of Mexico (in the 1877-1911 period) and South Korea (in the 1961-1979 period), two countries which entered the growth process under elite rule. As we will briefly discuss further below, it appears that-in both cases - a major tool to please the elites was to deliver institutions which provided the oligarchs with cheap access to capital-with consequences that are also reflected in the present model.

This paper combines two influential lines of research. On the one hand, we build on work by Aghion amd Bolton (1997), Piketty (1997), and Matsuyama (2000, 2006) who also

\footnotetext{
3 This implication is consistent with earlier influential work on economic growth in class-divided societies (e.g., Kuznets 1955; Kaldor 1956; Galor and Moav 2004) which regularly highlights that the poor (i.e., the workers) tend to have lower savings rates than the capitalists.
} 
analyze the evolution of the distribution when financial markets are imperfect. As in these papers, we focus on the interplay between the current wealth distribution and the (endogenous) rates of return which, in turn, determine the subsequent wealth distribution, and so on. ${ }^{4}$ There are, however, significant deviations from this literature in both the present model's setup and the focus of the paper. Regarding the modelling, this paper differs from earlier work by analyzing the impact of unequal returns to accumulation in the infinite-horizon framework where individuals take into account the whole future path of returns and wages. ${ }^{5}$ Concerning the focus, we depart from the literature by examining the dynamics of the distribution when economic institutions induce a clear "class structure" during certain periods of development.

On the other hand, there is an important relation to papers by Krusell and Ríos-Rull (1996), Rajan and Zingales (2003), Beck et al. (2003), Braguinsky amd Myerson (2007), Acemoglu (2008) and Galor et al. (2009), among others; all these contributions analyze the dynamics of economic institutions or policies in the process of development. Krusell and Ríos-Rull (1996) show how vested interests may result in policies preventing the adoption of more productive technologies. More closely, Rajan and Zingales (2003), Beck et al. (2003) and Braguinsky amd Myerson (2007) point out that a functioning credit market may work against the interests of the established large industrial firms. The former two papers suggest that weak creditor protection benefits the elite by preventing entry and hence suppressing competition in the product markets. Braguinsky amd Myerson (2007) argue that a better protection of outside investors increases capital inflows from abroad and hence drives up domestic wages-with negative consequences for the oligarchs' profits. The present paper, by contrast, highlights that weak creditor protection leads to vast redistributive effects by providing the elite with cheap access to credit during the process of development. Finally, Acemoglu (2008) constructs a model in which, as in this paper, the elite may redistribute from the workers through the introduction of entry barriers; in Acemoglu's paper, however, entry barriers do not keep capital costs low but the wage rate. Similarly, in Galor et al. (2009) the landed elite may oppose growth-promoting policies to suppress the price of labor (but, as in this paper, the elite may change its attitude at more advanced stages of development).

The remainder of this paper is organized as follows. Section 2 sets up the basic model. In Sect. 3, we discuss the impact of elite-protecting institutions on the dynamics of the economy and the welfare of the different groups in society. Section 4 endogenizes the evolution of the institutional environment over the process of development. In Sect. 5, the numerical analysis is presented. Section 6, finally, concludes.

\section{The model}

\subsection{Technology and social structure}

Technology and markets The economy is closed and comprises two sectors. First, there is a capital-intensive sector which produces a homogeneous intermediate good. For simplicity, the intermediate good is produced from capital alone. There is a large number of firms operating in this sector, and each of these firms has access to a linear technology which produces

\footnotetext{
4 Another series of enormously influential contributions includes papers by Banerjee and Newman (1991, 1993), Galor and Zeira (1993) and Mookherjee and Ray (2002); yet, unlike the work cited above, these papers rely on exogenous rates of return. There is also a related theoretical literature (e.g., Bénabou 1996; Aghion et al. 2005) which looks at the impact of credit market imperfections on growth.

5 Mookherjee and Ray (2003) and Banerjee and Duflo (2005) also analyze the impact of credit market frictions in an infinite-horizon setting. There are, however, substantial differences on the technology side.
} 
$A_{t}$ units of the intermediate good with one unit of capital, where $t$ denotes time and $A$ is assumed to grow at an exogenous rate $g_{A}{ }^{6}$ Aggregate sector output, $M_{t}$, is then simply given by

$$
M_{t}=A_{t} Q_{t},
$$

where $Q_{t}$ is aggregate capital invested in $t$. Capital can be exchanged in a credit market which is competitive in the sense that all agents take the borrowing rate $R_{t}$ as given. However, as described below, the possibility of ex post moral hazard will give rise to a credit market friction.

The second sector produces a unique final good using labor and the intermediate good as inputs. The sector also consists of a large number of firms, and each firm has access to an identical Cobb-Douglas production function. Since both the labor market and the market for the intermediate good are competitive, aggregate output, $Y_{t}$, is given by

$$
Y_{t}=L^{1-\alpha} M_{t}^{\alpha},
$$

where $L$ denotes aggregate labor supply and $0<\alpha<1$. Final output can be used for either consumption or investment, and the rate of transformation of final output into capital (or vice versa) is 1 . The final good is taken as the numeraire and its price is set equal to 1 .

The assumptions so far imply that the wage rate, $w_{t}$, and the price of the intermediate good, $p_{t}$, are given by their marginal products, and so we have

$$
w_{t}=(1-\alpha)\left(M_{t} / L\right)^{\alpha} \text { and } p_{t}=\alpha\left(M_{t} / L\right)^{\alpha-1} .
$$

The borrowing rate, by contrast, may deviate from the marginal product of capital, $p_{t} A_{t}$, because of the credit market friction.

Agents, endowments, and distortions The population size is constant over time and normalized to 1 . Individuals differ with respect to their initial endowments. There are two types of agents. A large fraction $\theta \in(0,1)$ of the population consists of workers. Each worker is endowed with $1 / \theta$ units of labor which are inelastically supplied in the labor market. In addition, each worker holds a non-negative amount of capital in $t=0$. The remaining individuals establish the economic elite and are referred to as oligarchs. Each member of the elite owns a "license" to operate a firm in the capital-intensive sector and is endowed with a strictly positive amount of capital in $t=0$. There are no further restrictions on the distribution of initial capital endowments (within or across groups), but it is natural to think that the average worker holds a lower endowment than the average oligarch does.

The economy features two distortions which are taken as exogenous for the moment (but are endogenized in Sect. 4 below). Together, these distortions give rise to what we will call an elite-protecting environment. The first distortion concerns market entry. Specifically, the workers cannot run firms in the capital-intensive sector of the economy because of prohibitive barriers to entry. As discussed in the previous section, such barriers may take the form of highly expensive licensing procedures, for instance. ${ }^{7}$ An immediate consequence is that the

\footnotetext{
6 In Sect. 4, we allow the institutional environment to affect the level of the path of $A$. For the moment, however, it is convenient to treat productivity as completely exogenous.

7 Alternatively, we can think that entry is prevented because, e.g., the state provides protection of productive assets only for the well-connected industrialists (as in Braguinsky amd Myerson 2007) or because regulations directly restrict the right to own productive assets to a certain group (as discussed in Aghion et al. 1999). Note, however, that the workers may be excluded even without these barriers if running a capital-intensive firm requires a minimum investment. Then, since the credit market is imperfect and own wealth serves as collateral, the relatively "poor" workers may not bring up sufficient capital in order to meet this requirement.
} 


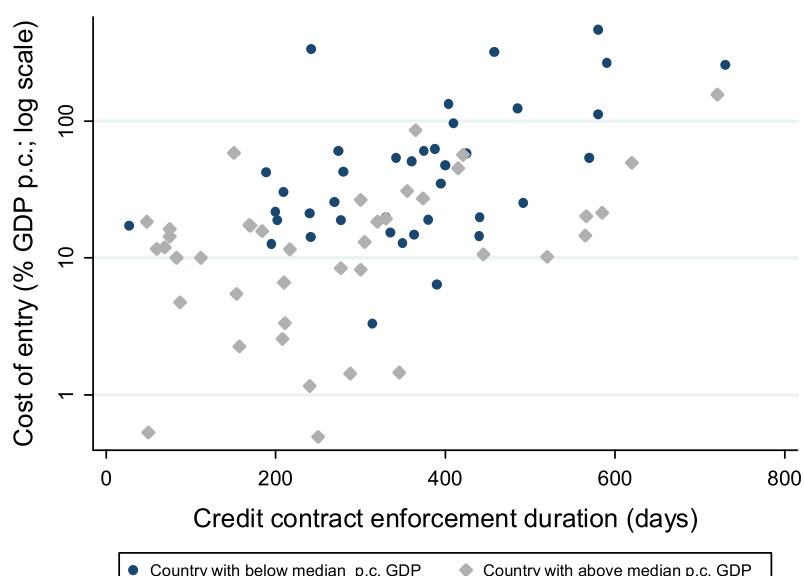

Fig. 1 Contract enforcement in courts and entry regulation. Sources: Number of days to enforce a simple debt contract in court: Djankov et al. (2005); cost as a share of per capita GDP to open a small business (and p.c. GDP): Djankov et al. (2002). Note: In total, we observe 83 countries. Three of these 83 observations (Italy, Poland, Slovenia) are excluded from Fig. 1 because they have been identified as outliers using the Hadi (1992) procedure

workers have to lend their saving to the oligarchs in order to get a positive return. But here is where the second distortion comes into play. While artificial barriers to entry over-protect the oligarchs, the lenders are ill-protected because of an enforcement problem. As we will explain below, the borrowers can default ex post on credit contracts at low cost. Intuitively, we may think that it is inexpensive for the oligarchs to stop or delay enforcement procedures.

Figure 1 illustrates that such distortions can be found in a sizable number of countries. The figure has a proxy for enforcement problems on its horizontal axis and a measure for regulatory barriers to entry on the vertical axis. ${ }^{8}$ There are 80 observations, and countries with a below-median GDP per capita are marked differently. Apparently, a high burden and weak creditor protection go hand in hand - and can be found predominantly in poorer economies. We will return to this specific pattern when we endogenize the institutional environment further below.

Assume now that the individuals in the range $[0, \theta]$ are workers and those in the range $(\theta, 1]$ are the oligarchs. Then, the aggregate labor endowment, the workers' aggregate capital stock, and the oligarchs' aggregate capital stock are given by $L \equiv \int_{0}^{\theta}(1 / \theta) \mathrm{d} i=1, K_{t}^{L} \equiv \int_{0}^{\theta} k_{i t} \mathrm{~d} i$, $K_{t}^{E} \equiv \int_{\theta}^{1} k_{i t} \mathrm{~d} i$, respectively, where $k_{i t}$ denotes capital owned by agent $i$ at date $t$.

\subsection{Credit market}

Credit relations and contract enforcement There is one possible type of credit contract. Oligarchs can borrow from workers in an economy-wide credit market. Ruling out other credit relations is simply for brevity since they neither would emerge in equilibrium nor would allowing them affect the equilibrium. The credit market is competitive in the sense that all agents take the borrowing rate $R_{t}$ as given. However, the market is imperfect in the sense that an oligarch cannot borrow any amount at this rate. The reason is an enforcement problem. In

\footnotetext{
8 The proxy for enforcement problems is the number of days required to enforce a contract of unpaid debt worth $50 \%$ of the country's GDP per capita. The regulatory burden is measured by the administrative cost (in GDP per capita, in logs) to set up a small firm. The data is from Djankov et al. $(2002,2005)$.
} 
particular, oligarch $i$ may default on the interest debt ( $\operatorname{credit} \cdot R_{t}$ ) by incurring a cost which is a fraction $\lambda \in(0,1]$ of his current gross income, $p_{t} A_{t} q_{i t}$, where $q_{i t}$ denotes the oligarch's capital investment. ${ }^{9}$ We will refer to $\lambda$ as the degree of protection of creditors. A $\lambda$ close to 0 stands for weak creditor protection because the borrowers can avoid the contractual payment obligations at a low cost. By contrast, $\lambda=1$ means perfect protection since the full gross income serves as "collateral" so that it never pays to break the contract later on.

Given these assumptions, an oligarch decides period by period whether to default or not, and he will do so whenever he can improve his period income. We further assume that the lenders take these incentives into account and give credit only up to the point where a borrower just pays back. It immediately follows that oligarch $i$ 's maximum amount of credit is given by $\lambda p_{t} A_{t} q_{i t} / R_{t}$. Thus, the oligarch's maximum firm size (as measured by the capital invested) can be calculated as $\bar{q}_{i t}=k_{i t}+\lambda p_{t} A_{t} \bar{q}_{i t} / R_{t}$. Solving for $\bar{q}_{i t}$ yields

$$
\bar{q}_{i t}=\frac{1}{1-\left(\lambda p_{t} A_{t} / R_{t}\right)} k_{i t}, \quad i \in(\theta, 1] .
$$

Equation (4) has two important properties. First, the maximum firm size is proportional to the oligarch's own capital stock, and the factor of proportionality is larger than 1 -which means that the oligarch's borrowing capacity increases in $k_{i t}$ (note that $R_{t}>\lambda p_{t} A_{t}$ in equilibrium). The reason is that punishment is a fraction of total output which is produced with borrowed capital but also with the oligarch's own capital holdings. Second, $\bar{q}_{i t}$ increases as the borrowing rate decreases. Other things equal, lowering $R_{t}$ reduces the benefit from breaking the contract while the cost remains unchanged, and so an oligarch can borrow up to a larger amount without being induced to break the contract ex post. Finally, notice that default does not occur in equilibrium. It is the possibility to default which renders the credit market imperfect.

Figure 2 shows oligarch $i$ 's optimal firm size (i.e., his optimal gross capital demand) as a function of $R_{t}$, given restriction (4) and the price of the intermediate good. If the borrowing rate exceeds the marginal product of capital, he will not seek credit at all but simply run a firm of size $k_{i t}$. If the borrowing rate equals the marginal product of capital, he is prepared to employ any amount of capital in his firm while restriction (4) limits the maximum firm size to $(1-\lambda)^{-1} k_{i t}$, and so the oligarch's gross capital demand may take any value on the interval $\left[k_{i t},(1-\lambda)^{-1} k_{i t}\right]$. Finally, in case of $R_{t}<p_{t} A_{t}$, the oligarch would like to get an infinite amount of credit since he can appropriate a rent on each unit borrowed. However, the maximum firm size is limited to $\bar{q}_{i t}$ (Eq. 4). This upper bound increases as the borrowing rate decreases and it approaches infinity as $R_{t}$ goes to $\lambda p_{t} A_{t}$.

Equilibrium borrowing rate We now turn to the aggregate level. Aggregate gross capital supply, $K_{t}$, is given by the sum of the workers' and the oligarchs' aggregate capital stocks, $K_{t}^{L}+K_{t}^{E}$. Aggregate gross capital demand is obtained by adding up the optimal firm sizes characterized above. Thus, given $p_{t}$, it equals $K_{t}^{E}$ if the borrowing rate exceeds the marginal product of capital; it lies on the interval $\left[K_{t}^{E},(1-\lambda)^{-1} K_{t}^{E}\right]$ if $R_{t}$ is equal to the the marginal product of capital; finally, it is given by $\left\{1-\left(\lambda p_{t} A_{t} / R_{t}\right)\right\}^{-1} K_{t}^{E}$ if the borrowing rate lies below the marginal product of capital (see Fig. 3).

\footnotetext{
9 As in Matsuyama (2000, 2006), there are no other costs like, for instance, limited access to credit in the future. While this assumption is made for analytical convenience, it can also be supported by arguing that there is a large number of potential lenders which do not share information about the borrowers' credit histories.
} 


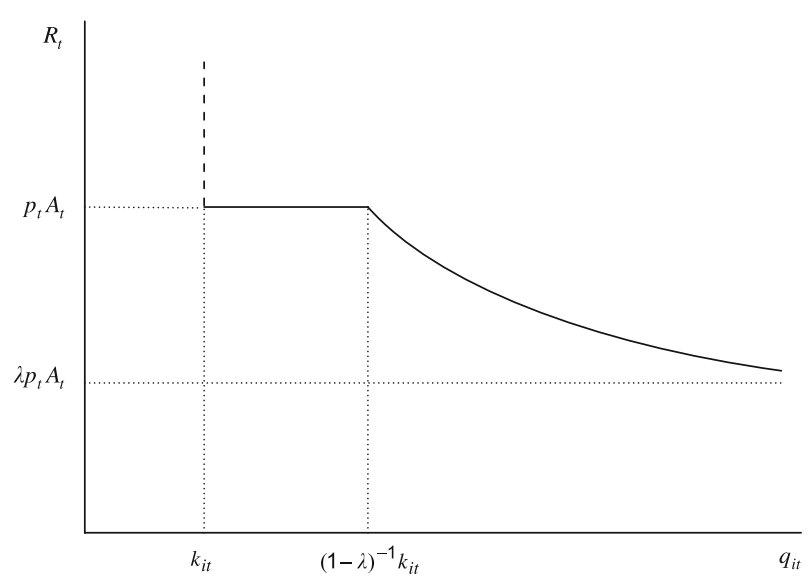

Fig. 2 Oligarch $i$ 's optimal firm size

(a) Low $\kappa$

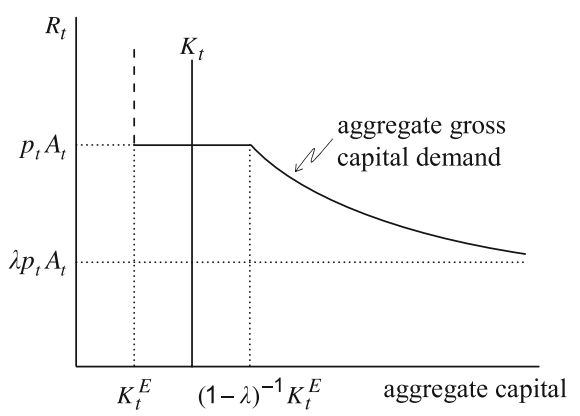

(b) High $\kappa$

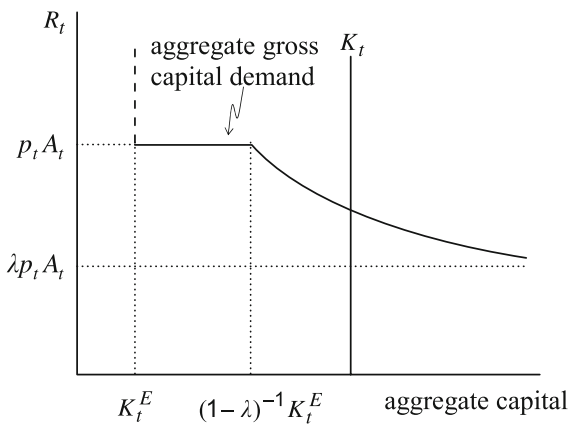

Fig. 3 Credit market equilibrium

The equilibrium borrowing rate has to equate gross capital demand and supply. As a result, we have $R_{t}=p_{t} A_{t}$ if $K_{t}^{E} \leq K_{t} \leq(1-\lambda)^{-1} K_{t}^{E}$ (see Fig. 3a). Otherwise, if

$$
\lambda<\frac{K_{t}^{L}}{K_{t}} \equiv \kappa_{t}
$$

gross capital demand would fall short of gross capital supply, $K_{t}$, if the borrowing rate were equal to the marginal product of capital (see Fig. 3b). Hence, $R_{t}$ has to be lower than $p_{t} A_{t}$ in order to give the borrowers weaker incentives to default. More precisely, we must have $R_{t}=\lambda p_{t} A_{t} / \kappa_{t}$ so that $K_{t}^{L}$ is exactly absorbed by the oligarchs. To summarize, we have

$$
r^{L}\left(K_{t} / B_{t}, \kappa_{t}\right)=R_{t}=\left\{\begin{array}{ll}
\frac{\lambda}{\kappa_{t}} p_{t} A_{t}=\frac{\lambda}{\kappa_{t}} \alpha\left(K_{t} / B_{t}\right)^{\alpha-1} & : \kappa_{t}>\lambda \\
p_{t} A_{t}=\alpha\left(K_{t} / B_{t}\right)^{\alpha-1} & : \kappa_{t} \leq \lambda
\end{array},\right.
$$

where $r^{L}$ denotes the workers' return to capital. To derive the last two equalities in Eq. (6) we substitute for $p_{t}$ and account for the fact that the whole capital stock will be employed 
$\left(Q_{t}=K_{t}\right) .{ }^{10}$ Moreover, we use the definition $B_{t} \equiv A_{t}^{\alpha /(1-\alpha)}$ to facilitate the exposition of the economy's intertemporal behavior (whereas $g$ will denote the growth rate of $B$ ).

The fact that the workers may face a return below the marginal product of capital is a result of the elite-protecting environment. Since the elite is shielded from entry, the workers have to lend in order to earn a positive return. But since creditors are insufficiently protected from opportunistic behavior by the borrowers, they may be forced to charge low borrowing rates: lower rates mean softer incentives to default so that the full credit supply can be allocated incentive-compatibly. As reflected in condition (5), the rate is more likely to be suppressed if either credit supply is relatively large or if the cost of opportunistic behavior is low. Clearly, these implications require that those who lack domestic business opportunities cannot too easily make (high-return) investments abroad. But since this constraint only applies to the "poor" workers, it seems not to be a particularly restrictive one.

Oligarchs' rate of return We now calculate the oligarchs' rate of return, $r_{t}^{E}$. Suppose first that $\kappa_{t}>\lambda$ so that $R_{t}$ lies below the marginal product of capital. Then, each oligarch seeks the maximum amount of credit and hence runs a firm of size $\bar{q}_{i t}$. In general, an oligarch's income is given by the firm revenue minus the interest debt so that, if $\kappa_{t}>\lambda$, oligarch $i$ earns $p_{t} A_{t} \bar{q}_{i t}-\left(\bar{q}_{i t}-k_{i t}\right) R_{t}$. Then, substituting for $\bar{q}_{i t}$ and $R_{t}$ (Eqs. 4, 6) yields

$$
\text { Oligarch } i \text { 's income }=\frac{(1-\lambda)}{\left(1-\kappa_{t}\right)} p_{t} A_{t} k_{i t}, \quad \kappa_{t}>\lambda .
$$

To calculate the rate of return, we have to divide the oligarch's income by his capital stock, $k_{i t}$, and so we get $r_{t}^{E}=(1-\lambda) p_{t} A_{t} /\left(1-\kappa_{t}\right)$. Finally, note that-if $\kappa_{t} \leq \lambda$ - the rate of return equals exactly the marginal product of capital. To summarize, we have

$$
r^{E}\left(K_{t} / B_{t}, \kappa_{t}\right)=\left\{\begin{array}{ll}
\frac{1-\lambda}{1-\kappa_{t}} p_{t} A_{t}=\frac{1-\lambda}{1-\kappa_{t}} \alpha\left(K_{t} / B_{t}\right)^{\alpha-1} & : \kappa_{t}>\lambda \\
p_{t} A_{t}=\alpha\left(K_{t} / B_{t}\right)^{\alpha-1} & : \kappa_{t} \leq \lambda
\end{array} .\right.
$$

Equations (6) and (7) highlight that there is a spread in the rates of return if $\kappa_{t}>\lambda$. In this case, the workers face a return below the marginal product while the oligarchs face one above since the additional income from each unit borrowed is larger than the rental rate. So, in contrast to the standard neoclassical model, the individual returns here do not only depend on the level of the aggregate capital stock but also on its distribution.

\subsection{Optimal consumption and aggregate dynamics}

This subsection analyzes the intertemporal decisions and derives the equations governing aggregate dynamics. To this end, we introduce the following definitions. We write $r_{t}^{L} \equiv$ $r^{L}\left(K_{t} / B_{t}, \kappa_{t}\right)$ and $r_{t}^{E} \equiv r^{E}\left(K_{t} / B_{t}, \kappa_{t}\right)$ if convenient. Moreover, a $(\widehat{\sim})$ over a variable denotes the variable divided by $B$, the transformed index of the state of technology. For example, we use the definition $\widehat{K}_{t} \equiv K_{t} / B_{t}$ and call $\widehat{K}$ the aggregate capital stock in efficiency units.

Optimal individual consumption All individuals derive utility from consumption of the final good. They divide their income in each period (as measured in units of the final good) into consumption and savings in a way that maximizes the intertemporal utility function

10 The equilibrium without an intermediate goods sector (i.e., if the final good were directly produced from $K$ and $L$ ) would be equivalent if punishment in case of default were a fraction $\lambda$ of firm revenues minus wages. 


$$
U_{i t}=\sum_{s=0}^{\infty}\left(\frac{1}{1+\rho}\right)^{s} \ln c_{i t+s}
$$

where $\rho$ and $c_{i t}$ denote, respectively, the rate of time preference and individual $i$ 's consumption at date $t$. Today's savings contribute one-to-one to the capital stock of tomorrow so that

$$
k_{i t+1}=\left(1+r_{i t}\right) k_{i t}+l_{i} w_{t}-c_{i t},
$$

where $r_{i t}=r_{t}^{L}, l_{i}=\frac{1}{\theta}$ if $i \in[0, \theta]$ and $r_{i t}=r_{t}^{E}, l_{i}=0$ otherwise. Individuals are forward-looking and can perfectly forecast the future values of the two state variables, $\widehat{K}_{t}$ and $\kappa_{t}$, and also those of the rates of return, $r_{t}^{L}$ and $r_{t}^{E}$, and the wage rate, $w_{t}=(1-\alpha) B_{t} \widehat{K}_{t}^{\alpha}$. Then, optimal behavior implies that consumption evolves according to the Euler equation,

$$
c_{i t+1}=\frac{1+r_{i t+1}}{1+\rho} c_{i t},
$$

and that initial consumption, $c_{i 0}$, is chosen in a way that satisfies the transversality condition

$$
\lim _{T \rightarrow \infty} \frac{k_{i T+1}}{\prod_{m=1}^{T}\left(1+r_{i t+m}\right)}=0 .
$$

Further, by using the Euler equation in the intertemporal budget constraint, we get

$$
c_{i t}=\frac{\rho}{1+\rho}\left(\left(1+r_{i t}\right) k_{i t}+h_{i t}\right),
$$

where $h_{i t}=\sum_{j=0}^{\infty}\left\{\left(1+r_{i t}\right) w_{t+j} l_{i} / \prod_{m=0}^{j}\left(1+r_{i t+m}\right)\right\}$ denotes agent $i$ 's present value of labor income. ${ }^{11}$ Substituting for $c_{i t}$ in Eq. (9) results in

$$
k_{i t+1}=\frac{1+r_{i t}}{1+\rho} k_{i t}+\left(w_{t} l_{i}-\frac{\rho}{1+\rho} h_{i t}\right) .
$$

Note that for $i \in(\theta, 1]$ we have $l_{i}=0$ and hence $h_{i t}=0$. Accordingly, as a result of the log-preferences, the oligarchs' optimal consumption behavior depends only on the current state of the economy and is independent of the future evolution of $K_{t}$ and $\kappa_{t}$.

Aggregate dynamics Since the returns to accumulation are identical within groups, individual behavior aggregates nicely. Summing up the individual consumption levels (Eq. 11) and standardizing yields aggregate consumption (in efficiency units),

$$
\widehat{C}_{t}=\frac{\rho}{1+\rho}\left(\left(1+\alpha \widehat{K}_{t}^{\alpha-1}\right) \widehat{K}_{t}+\widehat{H}_{t}\right)
$$

whereas the present value of the aggregate labor income (also in efficiency units) is given by

$$
\widehat{H}_{t}=\widehat{w}_{t}+\frac{(1+g) \widehat{w}_{t+1}}{\left(1+r_{t+1}^{L}\right)}+\frac{(1+g)^{2} \widehat{w}_{t+2}}{\left(1+r_{t+1}^{L}\right)\left(1+r_{t+2}^{L}\right)}+\cdots,
$$

and $g$ denotes the growth rate of the transformed productivity paramter $B$. Later on, it will be helpful to know the law of motion of $\widehat{H}_{t}$. Manipulating Eq. (14) yields

$$
\widehat{H}_{t+1}(1+g)=\left(\widehat{H}_{t}-\widehat{w}_{t}\right)\left(1+r_{t+1}^{L}\right) \text {. }
$$

11 Since the workers cannot borrow, it is implicitly assumed that they can follow this consumption rule without violating the $\left(k_{i t} \geq 0\right)$-constraint. This is indeed the outcome of all the simulations we have performed. 
Note that the distortions can affect aggregate consumption only via the future rates of return, $r_{t+1}^{L}, r_{t+2}^{L}, \ldots$, which, in turn, affect the present value of labor income (but-due to the linearity of the consumption function-not via redistributing current capital income).

Aggregating Eq. (9) across individuals and using the expression for aggregate consumption (Eq. 13) allows us to derive the law of motion of $\widehat{K}$ as

$$
\widehat{K}_{t+1}(1+g)=\frac{1}{1+\rho} \widehat{K}_{t}+\frac{1+\rho(1-\alpha)}{1+\rho} \widehat{K}_{t}^{\alpha}-\frac{\rho}{1+\rho} \widehat{H}_{t} .
$$

For further use below, we rewrite this equation slightly. Solving Eq. ( 15) for $\widehat{H}_{t}$ and using the resulting expression in Eq. (16) yields

$$
\widehat{K}_{t+1}(1+g)=\frac{1}{1+\rho} \widehat{K}_{t}+\frac{1}{1+\rho} \widehat{K}_{t}^{\alpha}-\frac{\rho}{1+\rho} \frac{\widehat{H}_{t+1}(1+g)}{1+r_{t+1}^{L}} .
$$

Two remaining issues need to be discussed at this point. First, our exposition shows that with $\lambda=1$ the economy here is formally equivalent to the textbook Ramsey-Cass-Koopmans model. The introduction of a protected intermediate goods sector, if not accompanied by imperfect enforcement, has no impact on aggregate dynamics. Second, we do not have a generic proof of the existence and uniqueness of the equilibrium if $\lambda<1$. However, a large number of simulations (see Sect. 5) have not led to any signs of non-existence or multiplicity.

\section{Comparative dynamics and the steady state}

This section compares the dynamics of the aggregate capital stock and its distribution in an elite-protecting economy to that in the corresponding first-best economy. The first-best economy features perfect contract enforcement and no entry barriers but is otherwise an identical copy of the former one, also with respect to the initial values of $\widehat{K}$ and $\kappa$. Throughout the analysis, it is assumed that $\widehat{K}_{0}$ lies below its first-best balanced-growth level so that the first-best economy converges to the corresponding steady-state values $\widehat{K}_{f b}^{*}$ and $\kappa_{f b}^{*}\left(\widehat{K}_{0}, \kappa_{0}\right)$. This notation makes transparent that, in the first-best world, the steady-state distribution of capital (but not the level of the capital stock) depends on the initial conditions. $^{12}$

We start the analysis by looking at the dynamics of the distribution in the first-best economy (Sect. 3.1). We then derive the comparative-dynamic results as well as the welfare implications (Sect. 3.2) and finally focus on convergence (Sect. 3.3).

\subsection{Behavior of the first-best economy}

To derive the behavior of $\kappa$ in case of the first-best economy, it is convenient to calculate the steady-state values of $\widehat{K}$ and $r$ first. These values are given by, respectively,

$$
\widehat{K}_{f b}^{*}=\left(\frac{\alpha}{\rho+g+\rho g}\right)^{\frac{1}{1-\alpha}} \text { and } 1+r_{f b}^{*}=(1+\rho)(1+g) .
$$

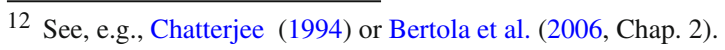


Moreover, the present value of labor income (in efficiency units) equals $(1+\rho) \rho^{-1} \widehat{w}_{f b}^{*}$ so that $H_{t}$ and $\left(1+r_{f b}^{*}\right) K_{t}$ (as well as output and consumption) grow at the same rate, $g$, in steady state-which is consistent with the fact that $\kappa$ is a constant on the balanced growth path. The lemma below relates this constant to $\kappa_{0}$. Note, however, that -although the economy converges to a particular value of $\kappa$-any level can be supported in steady state.

Lemma 1 In the first-best economy, the workers' share in aggregate capital, $\kappa$, converges from below towards its steady-state level, $\kappa_{f b}^{*}$. Formally, we have $\kappa_{t}<\kappa_{f b}^{*}\left(\widehat{K}_{0}, \kappa_{0}\right)$ for all $t \geq 0$.

\section{Proof See "Appendix".}

Lemma 1 highlights that, in the first-best economy, the workers have a relatively high propensity to save at early stages of development. As a result, if the initial capital stock is predominantly owned by the elite, the distribution grows more equal over time. The reason is the intertemporal behavior of $h_{i t}$, the present value of labor income: it turns out that, at low levels of accumulation, $h_{i t}$ is relatively low so that consumption induced by this wealth component, $(\rho /(1+\rho)) h_{i t}$, is also small. So, intuitively, the workers save a large part of their current labor income, $l_{i} w_{t}$, while their propensity to save out of capital income equals that of the oligarchs. As a result, the workers accumulate faster. ${ }^{13}$ Yet, the difference in the speed of accumulation decreases over time because $h_{i t}$ rises faster than the wages do.

It is further interesting to discuss Lemma 1 in the light of an earlier influential literature on economic growth in class-divided societies. For instance, contributions by Kuznets (1955) or Kaldor (1956) highlight that the wage earners tend to have a lower propensity to save than the capitalists. Clearly, Lemma 1 is inconsistent with these observations. Yet, Lemma 1 only applies in a benchmark case where the workers and the oligarchs have exactly the same opportunities to earn high returns on their wealth. It is the central topic of the following analysis to show that, consistent with the earlier literature, the workers' propensity to save is only low in the more realistic case of unequal access to economic opportunities.

\subsection{Comparative dynamics and welfare}

Comparative dynamics A direct implication of Lemma 1 is that the distortions have no impact if $\lambda$ is relatively high: if $\lambda$ exceeds $\kappa_{f b}^{*}\left(\widehat{K}_{0}, \kappa_{0}\right)$ and the workers stick to their first-best consumption level in $t=0, \kappa$ can grow towards $\kappa_{f b}^{*}$ without inducing a spread in the rates of return in the future (see Fig. 4, "high" $\lambda$ ). So the workers do not deviate from their first-best behavior at any point in time (and neither do the oligarchs) — which means that the dynamics towards the steady state are similar to that in the first-best economy.

In what follows, we focus on an economy with relatively weak creditor protection so that $\kappa_{f b}^{*}>\lambda$ (see Fig. 4, "low" $\lambda$ ). Then, elite-protecting institutions can be shown to have an impact on how the economy evolves. The starting point is to establish that aggregate consumption will be higher (relative to the first-best economy) at early stages of development:

Lemma 2 Let $\kappa_{f b}^{*}\left(\widehat{K}_{0}, \kappa_{0}\right)>\lambda$. Then, $\widehat{C}_{0}$ is strictly higher in the elite-protecting economy than in the first-best economy. Hence, $\widehat{K}_{1}$ must be smaller as compared to the first-best case.

Proof See "Appendix".

\footnotetext{
13 By looking at the growth rate of the individual capital stocks, $\left(k_{i t+1}-k_{i t}\right) / k_{i t}=\left(r_{t}-\rho\right) /(1+\rho)+$ $\left(l_{i} w_{t}-(\rho /(1+\rho)) h_{i t}\right) / k_{i t}$, we see that this result is not confined to our specific distribution of labor endowments. It would also hold if, e.g., labor were equally distributed (i.e., with $l$ and $h$ identical across agents). The result would be mitigated, however, if the oligarchs were also the largest wage earners.
} 


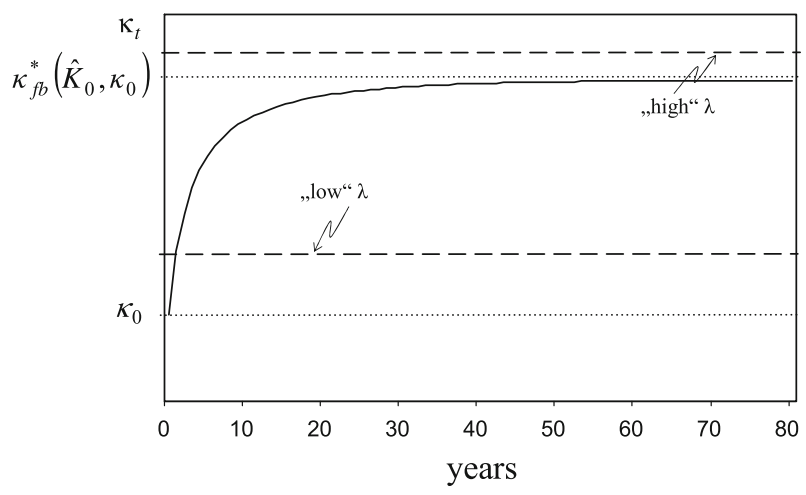

Fig. 4 Two cases

Lemma 2 shows that the elite-protecting environment is reflected in lower savings out of the aggregate income in $t=0$. The intuition is that low future returns to accumulation weaken the workers' incentives to save. More specifically, the elite-protecting environment alters the sequence of returns, $r_{1}^{L}, r_{2}^{L}, r_{3}^{L}, \ldots$, in a way that increases the present value of the labor income in $t=0$. Thus, the workers consume a larger part of their initial labor income (while the propensities to consume out of capital income are unchanged).

The next step is now to focus on the pace of capital accumulation in a longer perspective:

Proposition 1 Let $\kappa_{f b}^{*}\left(\widehat{K}_{0}, \kappa_{0}\right)>\lambda$. Then, $\widehat{K}_{t}$ is strictly lower in the elite-protecting economy than in the first-best economy for all $t>0$. Hence, we have $\widehat{K}_{t}<\widehat{K}_{f b}^{*}$ for all $t \geq 0$.

Proof See "Appendix".

An immediate implication of Proposition 1 is that the workers' share in aggregate capital is strictly lower in the elite-protecting economy from $t=1$ onwards: from Proposition 1 and Eq. (7), it follows directly that, with elite-protecting institutions, $r_{t}^{E}$ is strictly higher at all future dates $t>0$ no matter whether there is a spread in the rate of return $\left(\kappa_{t}>\lambda\right)$ or not $\left(\kappa_{t} \leq \lambda\right)$. Moreover, $r_{0}^{E}$ is equal or higher in the elite-protecting environment. Consequently, the oligarchs' aggregate capital stock, $K^{E}$, is equal or higher in $t=1$ and strictly higher (as compared to the first-best benchmark) at any date $t>1$ (Eq. 12). Since $K_{t}^{E} / K_{t}=\left(1-\kappa_{t}\right)$ and by Proposition 1, our claim follows. To summarize (proof in the text),

Proposition 2 Let $\kappa_{f b}^{*}\left(\widehat{K}_{0}, \kappa_{0}\right)>\lambda$. Then, $\kappa_{t}$ is strictly lower in the elite-protecting economy than in the first-best economy for all $t>0$.

So, by reducing the workers' propensity to save, the elite-protecting environment weakens the dynamics towards more equity in currently unequal societies. Thus, it is interesting to ask whether the workers' savings are still sufficiently large to push $\kappa$ beyond $\lambda$ if $\kappa_{0}<\lambda$ :

Proposition 3 Let $\kappa_{f b}^{*}\left(\widehat{K}_{0}, \kappa_{0}\right)>\lambda \geq \kappa_{0}$. Then, $\kappa$ rises above the threshold level $\lambda$ at some point in time. More generally, whenever $\kappa$ lies below $\lambda$, it must (again) be strictly higher in some future period (and thus we also have $\kappa_{f b}^{*}\left(\widehat{K}_{t}, \kappa_{t}\right)>\lambda$ for all $t>0$ ).

Proof See "Appendix".

Proposition 3 can be understood as follows. According to Lemma 2, the present value of the aggregate labor income, $\widehat{H}_{0}$, must be higher in the elite-protecting economy while 
Proposition 1 implies that, at any point in time, the wages (the marginal product of capital) are comparatively low (high) so that $\widehat{H}_{0}$ tends to be low. Proposition 3 states now that a slower accumulation and a higher present value of labor income can only go together when some time later the workers discount future labor income with less than the marginal product of capital. So there must be at least one period in which the workers' share in aggregate capital exceeds $\lambda$.

Proposition 3 also allows us to compare the growth rate of the elite-protecting economy in a given period $t$ with the rate that would prevail in a first-best economy which is at the same state, $\left(\widehat{K}_{t}, \kappa_{t}\right)$. Since $\kappa_{f b}^{*}\left(\widehat{K}_{t}, \kappa_{t}\right)>\lambda$ for all $t>0$, Lemma 2 applies at all points on the equilibrium path. Thus, it is always the case that the growth rate in the elite-protecting economy is strictly lower than the rate in a first-best economy at the same state.

Welfare implications These comparative-dynamic results lead to clear-cut welfare predictions: we already know that the oligarchs' rate of return, $r_{t}^{E}, t>0$, is strictly higher with elite-protecting institutions. Hence, due to the Euler equation, the oligarchs must be on a steeper consumption path (relative to first-best). Moreover, since the oligarchs' initial consumption level is equal to (in case of $\kappa_{0} \leq \lambda$ ) or higher than (in case of $\kappa_{0}>\lambda$ ) the benchmark level, they consume strictly more in each period $t>0$ - which means that their lifetime utility (8) is higher. Note further that, since the outcome in the first-best economy is on the utility possibility frontier, the workers must be worse off. To summarize (proof in the text),

Proposition 4 Let $\kappa_{f b}^{*}\left(\widehat{K}_{0}, \kappa_{0}\right)>\lambda$. Then, the oligarchs are strictly better off in the eliteprotecting economy than in the first-best economy. The workers, by contrast, are worse off.

Obviously, an important force behind the oligarchs' welfare gain is what Acemoglu (2008) calls a price-manipulation effect: by reducing incentive-compatible demand for credit, the elite-protecting environment puts the oligarchs in a collective monopsony position-which allows them to borrow at a rate below the marginal product of capital. ${ }^{14}$ There is, however, a second favorable mechanism: as shown in Proposition 1, weak creditor protection reduces the pace of aggregate capital accumulation so that the marginal product of capital is higher at each point in time. As a result, since the oligarchs derive income solely from capital, they would experience higher levels of income and consumption in each period even if they had to pay exactly the marginal product when borrowing (and the rents were appropriated by someone else). ${ }^{15}$ Put differently, this slowdown effect benefits the oligarchs because the factor from which they derive their income is relatively scarce at each point in time.

We now have established that weaker creditor protection lifts the oligarchs' lifetime utility relative to a situation with near-perfect enforcement $\left(\lambda \geq \kappa_{f b}^{*}\right)$. Yet, our theoretical analysis does not arrive at a clear-cut prediction on whether a lower $\lambda$ is uniformly associated with a higher lifetime utility. To see the reason, consider two economies which are again identical aside from creditor protection; moreover, assume that the two values of $\lambda$ are given by $\lambda^{h}$ and $\lambda^{l}$, whereas $\kappa_{0}>\lambda^{h}>\lambda^{l}$. Then, by looking at the borrowing rate, $R_{t}=\left(\lambda / \kappa_{t}\right) \alpha \widehat{K}_{t}^{\alpha-1}$, we immediately see that-in $t=0-$ the $\lambda^{l}$-economy experiences a

${ }^{14}$ However, in Acemoglu (2008) paper, it is the wage rate that is manipulated. This is also true in Braguinsky amd Myerson (2007) who-inter alia—show how poor protection of investments by outsiders depresses wages.

15 More formally, oligarch $i$ 's optimal consumption-savings behavior is described by $c_{i t}=(\rho /(1+\rho))$ $\left(1+r_{t}^{E}\right) k_{i t}$ and $k_{i t+1}=(1 /(1+\rho))\left(1+r_{t}^{E}\right) k_{i t}$. So, if $r_{t}^{E}$ declines at a lower rate, consumption in each period $t>0$ would be higher even if $r^{E}$ were given by the marginal product of capital. 


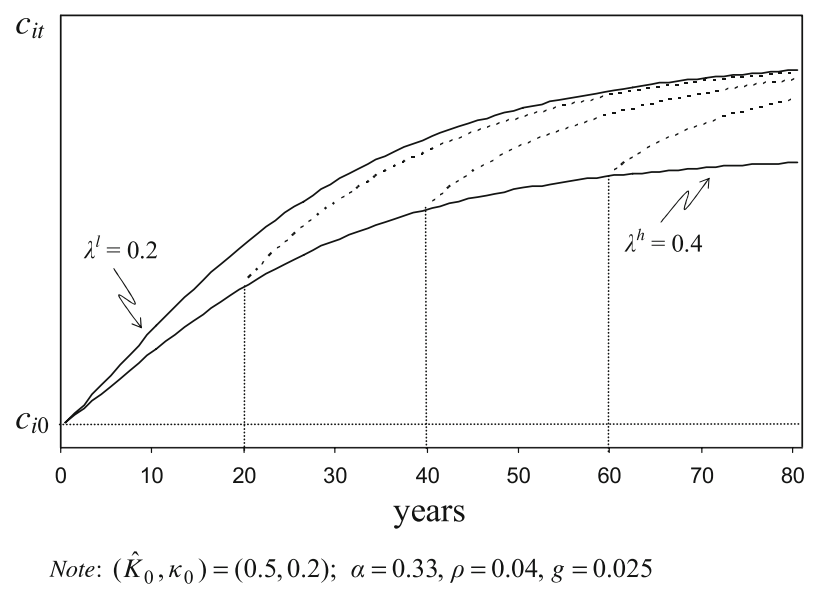

Fig. 5 Dynamics of the representative oligarch's level of consumption with different $\lambda \mathrm{s}$

stronger price-manipulation effect (i.e., we have $\left.\lambda^{l} / \kappa_{0}<\lambda^{h} / \kappa_{0}\right)$ so that the oligarchs' rate of return,

$$
r^{E}\left(\widehat{K}_{t}, \kappa_{t}\right)=\frac{1-\lambda}{1-\kappa_{t}} \alpha \widehat{K}_{t}^{\alpha-1},
$$

is unambiguously higher. Obviously, this result is due to the fact that-in a given periodcredit supply is inelastic. Yet, in a dynamic perspective, this is no longer true: as the workers save little in response to the low rates of return, future supply of credit in the $\lambda^{l}$-economy will be low. Put differently, the future values of the workers' share in aggregate capital, $\kappa_{1, \lambda^{l}}, \kappa_{2, \lambda^{l}}, \ldots$, will be comparatively small. Thus, unlike in the beginning, weaker creditor protection may be associated with a weaker price-manipulation effect later on. Note, however, that low future credit supply does not necessarily imply low future levels of $r^{E}\left(\widehat{K}_{t}, \kappa_{t}\right)$. If the workers save little, the sequence of capital stocks, $\widehat{K}_{1, \lambda^{l}}, \widehat{K}_{2, \lambda^{l}}, \ldots$, converges more slowly - which implies a milder decline in the marginal product of capital (and hence in $r^{E}$ ).

Thus, whether the elite prefers $\lambda^{l}$ over $\lambda^{h}$ is a priori unclear. The question is whether the benefits associated with a more powerful slowdown effect and a stronger initial pricemanipulation effect outweigh possible "losses" due to weaker price manipulation later on. Answering this question requires a comparative-dynamic analysis of the transitional paths of the two state variables which determine the dynamics of $r^{E}\left(\widehat{K}_{t}, \kappa_{t}\right)$ and hence the consumption path. Yet, since these paths cannot be pinned down explicitly, it is convenient to rely on simulations. Figure 5 gives a representative picture of the results. The two solid lines show the representative oligarch's consumption paths, with the upper graph reflecting the $\lambda^{l}$-economy. Clearly, the figure reveals that-in each period-consumption is higher in the $\lambda^{l}$-case. Thus, the oligarchs are strictly better off under weaker creditor protection.

The dashed lines, finally, reflect results from a slightly different experiment: each line shows the oligarch's consumption path after the $\lambda^{h}$-economy has experienced an unexpected fall in $\lambda$ (at three different points in time). Apparently, consumption consistently improves in the aftermath of such a change. Thus, given this parametrization, we not only find that the equilibrium associated with permanently low creditor protection leads to higher welfare. Figure 5 also suggests that —on the equilibrium path of the $\lambda^{h}$-economy-lowering $\lambda$ benefits 
the elite at any given point. Further simulations based on different parametrizations have not resulted in any conflicting findings. Some of these simulations are presented in Sect. 5.

\subsection{Convergence and the steady state}

In order to discuss convergence under elite-protecting institutions, we first have to establish the existence of a steady state. From above, we know that the first-best economy is on a balanced growth path if the aggregate capital stock (in efficiency units) equals $\widehat{K}_{f b}^{*}$. We further know that the distribution of capital is constant under balanced growth. From this, it follows that also in the elite-protecting environment any combination of state variables $\left(\widehat{K}_{f b}^{*}, \kappa\right), \kappa \in[0, \lambda]$, is consistent with steady-state growth: under these circumstances, we have $r^{L}=r^{E}=r_{f b}^{*}$ so that the dynamics do not differ from those in the first-best economy. In particular, $\kappa$ is a constant so that imperfect creditor protection may never play a role.

We now proceed by looking at the accumulation process in the elite-protecting economy:

Lemma 3 Let $\kappa_{f b}^{*}\left(\widehat{K}_{0}, \kappa_{0}\right)>\lambda$ and $r_{0}^{L} \geq r_{f b}^{*}$. Then, we have $\widehat{K}_{t+1}>\widehat{K}_{t}$ for all $t \geq 0$.

Proof See "Appendix".

Lemma 3 states that the individuals' optimal consumption decisions will never give rise to negative aggregate savings. The intuition is the same as in the first-best economy. Negative aggregate savings in $t$ are associated with a higher return to capital in $t+1$. Then, since the Euler equation determines consumption growth, aggregate consumption will expand strongly between the two periods so that aggregate savings are even lower in $t+1$. This, in turn, leads to a strong expansion of consumption between $t+1$ and $t+2$, and so on. Eventually, the economy would collapse if the individuals followed such a consumption path.

So far, we know that even in the elite-protecting economy the aggregate capital stock monotonically increases (Lemma 3 ) but may never exceed $\widehat{K}_{f b}^{*}$ (Proposition 1). Suppose now that $\widehat{K}$ does not converge to $\widehat{K}_{f b}^{*}$ but to a level that lies strictly below $\widehat{K}_{f b}^{*}$. Then, by Eq. (7), we have $1+r_{t}^{E}>1+r_{f b}^{*}=(1+\rho)(1+g)$ for all $t \geq 0$. Consequently, since

$$
\widehat{K}_{t+1}^{E}=\frac{1+r_{t}^{E}}{(1+\rho)(1+g)} \widehat{K}_{t}^{E},
$$

$\widehat{K}^{E}$ has to grow towards infinity. This, in turn, requires $\widehat{K}^{L}$ to become negative from some point onwards which is impossible since the workers cannot borrow. ${ }^{16}$ Hence, the aggregate capital stock must converge to $\widehat{K}_{f b}^{*}$. Then, by the Eqs. (16) and (13), we have $\lim _{t \rightarrow \infty} \widehat{H}_{t}=$ $(1+\rho) \rho^{-1} \widehat{w}_{f b}^{*}=\widehat{H}_{f b}^{*}$ and $\lim _{t \rightarrow \infty} \widehat{C}_{t}=\widehat{C}_{f b}^{*}$, respectively. To summarize (proof in the text),

Proposition 5 Let $\kappa_{f b}^{*}\left(\widehat{K}_{0}, \kappa_{0}\right)>\lambda$ and $r_{0}^{L} \geq r_{f b}^{*}$. Then, aggregate capital, $\widehat{K}$, and aggregate consumption, $\widehat{C}$, converge to their corresponding first-best steady-state values, $\widehat{K}_{f b}^{*}$ and $\widehat{C}_{f b}^{*}$.

We now look at the limit behaviour of $\kappa_{t}$. Note that this ratio cannot converge to a value on the interval $(\lambda, 1]$ since the oligarchs' rate of return would converge to a level that is strictly higher than $r_{f b}^{*}=(1+\rho)(1+g)-1$. Then, once again, the oligarchs' stock of capital would grow towards infinity. Note further that $\kappa_{t}$ does not converge to a value on the interval $[0, \lambda)$ either because of Proposition 3. However, $\kappa_{t}$ can be shown to converge exactly to $\lambda$ :

${ }_{16}$ Note, however, that even if the workers were allowed to borrow, $\widehat{K}$ could not converge to a value below $\widehat{K}_{f b}^{*}$. The reason is that $\widehat{C}$ would grow towards infinity. 
Proposition 6 Let $\kappa_{f b}^{*}\left(\widehat{K}_{0}, \kappa_{0}\right)>\lambda$ and $r_{0}^{L} \geq r_{f b}^{*}$. Then, the workers' share in aggregate capital, $\kappa$, converges to $\lambda$.

Proof See "Appendix".

Propositions 5 and 6 highlight a certain asymmetry in the impact of elite-protecting institutions. While such an environment does not prevent the aggregate capital stock from converging to its first-best level, it may have a large impact on the long-run distribution of capital. These results are, however, two sides of the same coin. While weakening the workers' incentives to save, elite-protecting institutions induce the oligarchs to accumulate fast so that-over time - the elite's share in the aggregate capital stock becomes sufficiently large to render the borrowing constraints insignificant. As a result, the gap between the workers' and the oligarchs' return to accumulation is set to vanish. But this also means that the aggregate variables eventually evolve as in an undistorted economy - and thus converge to their first-best levels.

\section{Endogenous productivity and institutions}

We now continue the analysis by modifying the existing framework in two natural dimensions. First, we allow the elite-protecting environment to affect productivity. Second, adopting a political-economy perspective, we endogenize the dynamics of the institutional environment over the process of development.

\subsection{A simple extension}

Institutions and productivity The ramifications of poor contract enforcement may not be confined to the financial system. A further important concern is that weak contracting institutions limit the access to crucial foreign input factors (such as "technology"). ${ }^{17}$ For concreteness, suppose that oligarch $i$ 's output is no longer given by an exogenous parameter $A_{t}$ times capital invested but instead by $\widetilde{A}_{i t}\left(z_{i t}, q_{i t}\right) \cdot q_{i t}$, where $z_{i t}$ denotes the quantity of an additional input factor which can be bought in a perfectly competitive international market. We will refer to this factor simply as the "technology good," and we impose

$$
\widetilde{A}_{i t} \equiv \widetilde{A}\left(z_{i t}, q_{i t}\right)=\left(\frac{z_{i t}}{q_{i t}}\right)^{\gamma},
$$

where $0<\gamma<1$. The price of the technology good is given by $\chi$ units of the intermediate good so that the total cost reads $p_{t} \chi z_{i t}$ when expressed in terms of the final good. Technology contracts are subject to the same type of enforcement problems as credit contracts are. Specifically, oligarch $i$ can default ex post on the payment obligation by incurring a cost which is given by $\lambda$ times the current firm revenue, $p_{t} \widetilde{A}_{i t} q_{i t}$. As a result, incentive compatibility requires $\lambda p_{t} \widetilde{A}_{i t} q_{i t} \geq p_{t} \chi z_{i t}$ so that default does not occur in equilibrium. Note further that, in case of default on the credit contract, it is now convenient to assume that the punishment is given by $\lambda$ times the firm revenue net of the total cost of technology.

An oligarch's intra-temporal decision problem now involves two choice variables, $q_{i t}$ and $z_{i t}$, and these variables are chosen to maximize the oligarch's income, $p_{t} \widetilde{A}_{i t} q_{i t}-R_{t}\left(q_{i t}-\right.$

\footnotetext{
17 Related arguments can be found in Antràs and Helpman (2004) in the context of a Ricardian trade model. See also Acemoglu et al. (2007) for a model in which weak contracting institutions lead to the choice of less advanced technologies. Similarly, Erosa and Hidalgo Cabrillana (2008) demonstrate how poor (credit) contract enforcement can lead to the inefficient use of low-productivity technologies.
} 
$\left.k_{i t}\right)-p_{t} \chi z_{i t}$, subject to the two incentive-compatibility constraints $\lambda p_{t}\left(\widetilde{A}_{i t} q_{i t}-\chi z_{i t}\right) \geq$ $R_{t}\left(q_{i t}-k_{i t}\right)$ and $\lambda p_{t} \widetilde{A}_{i t} q_{i t} \geq p_{t} \chi z_{i t}$. The solution to this decision problem is derived in the appendix. It turns out that the equilibrium firm size as measured by capital invested remains as discussed in Sect. 2.2 and shown in Fig. 2-with the exception that $A_{t}$ is replaced by $A(\lambda)$, a constant which is pinned down by the equilibrium factor intensity as discussed below. As a result, the equations determining $r_{t}^{L}$ and $r_{t}^{E}$ retain their form as well. More generally, $A_{t}$ has to be replaced by $A(\lambda)$ in all the existing equations but the functional forms remain unaffected. Turning to factor intensity, we get that $\widetilde{A}_{i t}$ is given by $(\lambda / \chi)^{\gamma /(1-\gamma)}$ if $\lambda<\gamma$ and by $(\gamma / \chi)^{\gamma /(1-\gamma)}$ otherwise, whereas the latter expression stands for the unconstrained-optimal choice. So, in the present environment, weak contract enforcement can actually lead to a static inefficiency by restricting the quantity of foreign inputs to a sub-optimal level.

To assess the impact of weak contract enforcement on aggregate income, we have to determine the oligarch's net output, i.e., output minus the cost of technology:

$$
\text { Oligarch } i \text { 's net output }=A(\lambda) q_{i t}=\left\{\begin{array}{l}
(\lambda / \chi)^{\gamma /(1-\gamma)}(1-\lambda) q_{i t}: \lambda<\gamma \\
(\gamma / \chi)^{\gamma /(1-\gamma)}(1-\gamma) q_{i t}: \lambda \geq \gamma
\end{array}\right.
$$

From this, we can immediately infer that the extended framework is formally equivalent to the basic version with a modified aggregate production function in the capital-intensive sector:

$$
M_{t}=A(\lambda) Q_{t} .
$$

So, in contrast to the baseline world, weak contract enforcement not only retards growth by distorting savings incentives but may also hamper economic development by depressing the level of productivity in the capital-intensive sector of the economy.

Below, it will be convenient to directly rely on the reduced-form representation of the technology as shown in Eq. $\left(1^{\prime}\right)$. Moreover, to simplify the exposition, we assume that all oligarchs get the same initial capital endowment. Finally, note that - as in the previous sections-we can have exogenous "technological progress" by augmenting $\widetilde{A}_{i t}$ with a factor that steadily grows, and so we will sometimes write $A_{t}(\lambda)$ instead of just $A(\lambda)$.

Political power and institutional choices While the distortions have been treated as exogenous so far, we now allow for endogenous changes over time. The focus is on an oligarchy where, in every period, economic institutions are determined by (majoritarian voting among) the elite. ${ }^{18}$ There are two dimensions, the quality of contract enforcement and the extent of entry barriers. Regarding the first dimension, there are two options, $\lambda_{t} \in\{\underline{\lambda}, \bar{\lambda}\}$, where $\underline{\lambda}<\bar{\lambda}$. In reality, switching from weak enforcement to strong enforcement can be achieved by, for instance, an organizational reform which gives the judges stronger incentive to decide accurately; by hiring more judges (and paying them better); or by promoting the most able judges into important positions. Clearly, some of these measures are costly. For the moment, however, we abstract from this point but return to it below. We further impose $\underline{\lambda}<\gamma$ and $\bar{\lambda}=1$ which means that, if $\underline{\lambda}$ is implemented, productivity in the capital-intensive sector is impaired whereas $\bar{\lambda}$ is associated with first-best productivity. This parametrization guarantees that the elite faces an interesting trade-off when deciding on enforcement. A final restriction comes from the notion that, in practice, once powerful and reliable law-enforcement systems are created, it is difficult to turn back the clock due to the resistance of the institutions

18 Under democracy (i.e, with majoritarian voting among the whole population) the outcome would always be "perfect contract enforcement" and "no barriers to entry" since the median voter is a worker. 
themselves. ${ }^{19}$ So we model $\bar{\lambda}$ as an absorptive choice, i.e., a choice that cannot be reverted later on.

The second institutional choice pertains to the possibility of entering the capital-intensive sector. Also in this dimension, there are two options, "entry permitted" or "entry prohibited." As discussed in Sect. 2 , the latter option can take the form of prohibitively expensive procedures to acquire a business license (with which the oligarchs are endowed). Note that the optimal choice in this respect is closely related to that of $\lambda$ : maintaining weak contract enforcement can only benefit the elite if the workers remain excluded, and so opting for $\lambda_{t}=\underline{\lambda}$ also means opting for "entry prohibited." On the other hand, if $\lambda_{t}=\bar{\lambda}$, we are back in the first-best world and so prohibiting entry (or allowing it) has no implications anymore. For this reason, we no longer explicitly address entry barriers but take for granted that $\lambda_{t}=\underline{\lambda}$ is associated with "entry prohibited" (while $\lambda_{t}=\bar{\lambda}$ may be associated with "entry permitted").

The institutional setting is determined at the very beginning of each period $t$ (as long as $\lambda_{t-1}=\underline{\lambda}$ ) and becomes effective immediately. Moreover, since all elite members are identical, they prefer the same options, and so we can focus on the choice of the representative oligarch.

Limited knowledge Finally, as long as the elite-protecting environment is in place, we find it plausible to impose a restriction on the workers' knowledge about the technology in the capital-intensive sector: being excluded from this sector anyway, the workers are unaware of the fact that switching to perfect enforcement would lift the productivity of capital. Instead, if the oligarchs opt for elite-protecting institutions in the beginning $\left(\lambda_{0}=\underline{\lambda}\right)$, the workers take as invariable the level (of the path) of $A$ as observed in $t=0 .{ }^{20}$ As will become clear, this assumption implies that a potential switch to perfect enforcement comes unexpectedly for the workers (though not for the elite). Besides being a reasonable approximation to reality, this assumption allows us to analyze institutional change in a tractable way.

\subsection{Analysis and discussion}

We now derive the model's implications regarding the dynamics of the institutional environment. The following results are obtained under initial conditions similar to those in Sect. 3 . So the focus is on an economy where capital is "scarce" in the beginning. More precisely, we impose $\widehat{K}_{0, \lambda}=K_{0} / B_{0}(\underline{\lambda})$ to lie below the (first-best) steady-state level, whereas again $B_{t}(\lambda) \equiv A_{t}(\lambda)^{\alpha /(1-\alpha)}$. Moreover, we continue to assume that $\underline{\lambda}$ is sufficiently small so that it affects the workers' consumption-savings behavior (i.e., we still impose $\left.\underline{\lambda}<\kappa_{f b}^{*}\left(\widehat{K}_{0, \underline{\lambda}}, \kappa_{0}\right)\right)$.

Institutional change The first step is to determine how the oligarchs' attitude towards eliteprotecting institutions changes over time. Suppose that the elite has chosen $\lambda_{0}=\underline{\lambda}$ so that there is room for improvement later on. Clearly, a possible future switch to perfect enforcement must come unexpectedly for the workers: if improving enforcement did not enhance productivity, it would be in the oligarchs' interest to preserve the elite-protecting environment

\footnotetext{
19 This is not to argue that reversals are impossible. Nevertheless, once a large number of high-quality judges are promoted to tenured positions and powerful supervisory bodies are installed, it would certainly require costly fights (which might even threaten the rule of the elite) to return to the old system.

20 Formally, they believe the elite to rely on the factor intensity $(\underline{\lambda} / \chi)^{\gamma /(1-\gamma)}$ even after a switch to $\bar{\lambda}$ due to the lack of information about the elite's access to the foreign good. The oligarchs rely indeed on this intensity as long as $\lambda_{t}=\underline{\lambda}$ but choose $(\gamma / \chi)^{\gamma /(1-\gamma)}$ after a switch to $\bar{\lambda}$ (which is then observed by the workers).
} 
at each point on the equilibrium path associated with $\lambda_{0}=\lambda_{1}=\cdots=\underline{\lambda} .{ }^{21}$ As a result, the workers' consumption-savings behavior is as if the elite-protecting environment were in place forever. Moreover, also the oligarchs' current consumption decisions are unaffected by a possible future switch to $\bar{\lambda}$ : deriving income exclusively from capital, consumption by oligarch $i,(\rho /(1+\rho))\left(1+r_{t}^{E}\right) k_{i t}$, is just a function of the current capital stock and the current rate of return. Thus, as long as $\lambda_{t}=\underline{\lambda}$, all variables evolve as if $\underline{\lambda}$ were in place forever. Relying on this insight, we can now prove the following result:

Proposition 7 Suppose that the elite has chosen $\lambda_{0}=\underline{\lambda}$. Then, the politico-economic equilibrium path entails a swtich to perfect enforcement $(\overline{\bar{\lambda}}=1)$ at some point $t>0$ in the future.

\section{Proof See "Appendix".}

The driving force behind this change in policy preferences is the endogenous evolution of the aggregate capital stock and its distribution. Intuitively, with the low level of enforcement permanently in place, $\kappa$ would grow arbitrarily close to $\underline{\lambda}-$ which means that the rents from the price-manipulation effect slowly fade away. Similarly, as $\widehat{K}_{t, \underline{\lambda}}$ approaches its steady-state level, the benefits from the slowdown-effect diminish. Put differently, elite-protecting institutions influence the dynamics of the two state variables in a way that makes the rents lose significance over time. Thus, at some point, it must become optimal to strengthen contract enforcement in order to improve access to productivity-enhancing inputs.

For further use below, note also that the representative oligarch's initial utility under invariably weak enforcement (i.e., with $\lambda_{0}=\lambda_{1}=\cdots=\underline{\lambda}$ ) is just a lower bound of the level associated with the politico-economic equilibrium path: as long as contract enforcement is weak, the economy evolves exactly as if $\underline{\lambda}$ were in place forever. However, at the moment of the improvement, the continuation value on the equilibrium path is strictly higher than the continuation value associated with the invariably low $\lambda$.

Early institutions The ultimate step is now to discuss under which circumstances the elite opts for $\lambda_{0}=\underline{\lambda}$. To do so, suppose first that $\gamma \leq \underline{\lambda}$ so that implementing $\underline{\lambda}$ does not result in a productivity loss $(B(\bar{\lambda})-B(\underline{\lambda})=0)$. Then, by Proposition 4 , implementing and indefinitely preserving $\underline{\lambda}$ (i.e., $\lambda_{0}=\lambda_{1}=\cdots=\underline{\lambda}$ ) would lead to a discrete increase in the representative oligarch's initial utility level (relative to perfect enforcement). As a result, this sequence would continue to be welfare-improving if the productivity differential $B(\bar{\lambda})-B(\underline{\lambda})$ were sufficiently close to zero but not exactly zero (i.e., if $\gamma$ were larger but sufficiently close to $\underline{\lambda}$ ). Thus, since the initial utility level associated with a constantly low $\lambda$ is just a lower bound of the equilibrium level, there must exist a sufficiently small productivity differential so that $\lambda_{0}=\underline{\lambda}$ (in combination with "entry prohibited") is the optimal choice by the elite. ${ }^{22}$

Section 5 goes through a number of simulations to address further interesting questions, in particular regarding the impact of the initial conditions on early institutions and the size of the welfare effects. Moreover, we will look at the timing of institutional change. The following proposition summarizes our exposition so far (proof in the text):

Proposition 8 Consider an economy where capital is "scarce" (i.e., where $\widehat{K}_{0, \lambda}$ is below the steady-state level). Then, on the politico-economic equilibrium path,

21 If creditor protection is invariably weak, we have $\kappa_{f b}^{*}\left(\widehat{K}_{t, \underline{\lambda}}, \kappa_{t}\right)>\underline{\lambda}$ for all $t>0$ (Proposition 3 ) so that Proposition 4 applies at each point on the equilibrium path.

22 In this context, it is also interesting to get a sense for the burden required to just prevent a worker from acquiring a license at some point before the switch to $\bar{\lambda}$. Relying on the baseline parametrization discussed in Sect. 5 , this critical burden would be $108 \%$ of the current GDP p.c. if $\underline{\lambda}=0.2$ (and $90 \%$ if, e.g., $\underline{\lambda}=0.4$ ). 
(i) the elite opts for $\lambda_{0}=\underline{\lambda}$ unless the associated productivity loss exceeds a certain strictly positive level (whose relationship to the initial conditions is numerically assessed in Sect. 5);

(ii) in case of $\lambda_{0}=\underline{\lambda}$, the elite will switch to perfect enforcement $(\bar{\lambda}=1)$ at some point $t>0$ in the future (for which Sect. 5 also provides an intuition).

Discussion Our results may deliver new insights into potential forces behind the high incidence of distortionary institutions among less-advanced economies (see, e.g., Fig. 1). The analysis suggests that, at early stages of development, the oligarchs have strong incentives to push for prohibitive barriers to entry and weak contracting institutions-even if this combination came at a cost in terms of lower productivity. Intuitively, with capital still scarce in the economy, elite-protecting institutions provide the elite with cheap access to credit-which has a huge impact on the profitability of the elite-run firms. Moreover, by depressing the workers' incentives to save, the pace of aggregate capital accumulation is reduced so that the return to accumulation declines less sharply over time-which benefits the major owners of capital. So, if the elite is politically powerful, a country at the onset of the accumulation process is likely to adopt such a combination of distortions. In more advanced economies, however, the benefits from elite-protecting institutions become minor as a result of the evolution of the capital stock and its distribution. What remains is just the "cost" in terms of lower productivity due to limited access to other input factors. So while the model predicts (oligarchic) regimes to favor elite-protecting institutions at early stages of development, these governments may well favor more open structures after a few decades.

In reality, there are additional forces which contribute to such a pattern. For instance, as discussed in Acemoglu (2008) or Caselli and Gennaioli (2006), entrepreneurial talent may be imperfectly correlated across generations; hence, restricting business to the incumbents turns increasingly costly. Similarly, as highlighted by Galor and Moav (2004, 2006), credit constraints become more and more of a burden if they prevent the average citizen from acquiring education: with low human capital investments, the return to physical capital is bound to decrease sharply over the process of development—which hurts the elite. On the other hand, there are also forces which might delay institutional change. For instance, if maintaining an efficient court system is costly and requires higher taxes (as, e.g., argued in Acemoglu and Verdier (1998)), the net benefit from stronger enforcement is smaller-which means that improving enforcement becomes optimal at an even later stage (see Sect. 5 below). Moreover, in the present set-up, removing the distortions leads to a decline in wealth inequality as the economy approaches its steady state. Thus, if the oligarchs' political clout rests on their high relative wealth, they might prefer to maintain the elite-protecting environment to secure political power (whose loss could be associated with higher taxes, for instance).

To conclude this section, we briefly review some historical accounts from Mexico's Porfirian era (1877-1911) which marks the start of the country's process of development. At the time, access to economic opportunities was highly unequal. Coatsworth (1978, p. 92), for instance, reports that "public regulations of economic activity (...) raised start-up costs and discouraged enterprise." At the same time, creditors could not rely on the judiciary when dealing with a defaulting debtor because, as Haber (1991, p. 567) reports, "it was extremely difficult to enforce loan contracts [through courts]." Yet, weak enforcement was not the only reason why an outsider was virtually unable to get a bank credit. In addition, the government deliberately hampered entry into the banking sector by applying a restrictive licensing policy. Apparently, the purpose behind these policies was to benefit a small number of economic and political elites. On the one hand, as highlighted here, the combination of weak contract enforcement and restrictive banking regulations suppressed incentive-compatible demand for 
credit by excluding those outside the elite from the banking system-and hence guaranteed relatively cheap access to capital for a small number of well-established financiers/industrialists who mainly invested the borrowed funds in their own enterprises. Maurer (2002, Chap. 5) highlights that such profitable auto-préstamo (insider lending) was the standard practice during the Porfirian era. On the other hand, in addition to winning crucial political support from the oligarchs and securing financing for the government, the politicians could appropriate part of the rents by receiving low-interest loans for their own industrial endeavors (Haber et al. 2003, Chaps. 3, 4). Note, finally, that the country's credit markets remained under-developed during whole era: even after three decades of growth, aggregate savings in the banking system were still small (Haber et al. 2003). During the same period, however, the elite-run enterprises grew exceptionally large-even by US standards (Maurer 2002, Chap. 6). The model's predictions are also consistent with these observations. ${ }^{23}$

\section{Simulations}

This section goes through a numerical exercise in order to highlight additional qualitative properties of the model but also to look at the quantitative side. Specifically, Sect. 5.1 looks at the welfare effects associated with elite-protecting institutions while Sect. 5.2 focuses on the timing of institutional change. As for the quantitative implications, the goal is to provide a sense of the magnitudes for reasonable parameter values and initial conditions.

\subsection{Magnitude of the welfare implications}

The focus here is on the welfare implications for the representative member of the elite. To quantify these welfare effects, we ask-for different levels of $\lambda$-what deterioration in the country's production possibilities is required to offset the benefits associated with eliteprotecting institutions. More precisely, we compute the compensating downward shift of the entire path of the productivity parameter $B=A^{\alpha /(1-\alpha)}$ if elite-protecting institutions were permanently introduced in $t=0 .{ }^{24}$ While this is an illustrative way to quantify utility changes in real terms, the resulting numbers have also a clear interpretation in the context of Proposition 8: they constitute a lower bound for the maximum productivity differential the elite is prepared to accept in exchange for the introduction of elite-protecting institutions in the beginning.

Parametrization Regarding the parametrization of the model, we take a period to represent 1 year and rely on $\alpha=0.33, \rho=0.04$ and $g=0.025$ so that the labor share is given by two-thirds of the GDP and the steady-state rate of return is $6.6 \%$ p.a. Note that we do not

\footnotetext{
${ }^{23}$ More recent evidence comes from fast-industrializing South Korea during the Park years (1961-1979). Also in this case, the ruler had close ties with the elites (i.e., the cheabol-owners; Chang 2003) and the main tool to please the elites was to deliver policies which provided them with cheap access to capital (Kang 2002a, b). These low-interest loans were highly beneficial to the oligarchs: in the 1960s, they were prepared to pay up to $20 \%$ of the loans in kickbacks. At the same time, the total amount of capital available in the banking system remained only low-which again did not prevent the cheabols from growing exceptionally large. Major reforms took place only in the 1980s when the system became too inefficient even for the elites. According to Treisman (1995), Russia went through a similar experience in the early 1990s. Finally, Rose-Ackerman (1999, pp. 10-11) reports analog practices from some of today's least-advanced economies, notably Kenya and Pakistan.

${ }^{24}$ It is more convenient to express the shift in terms of the transformed productivity parameter $B$ (rather than in $A$ ) because the resulting numbers give at the same time the impact on the long-run output level.
} 
have to take a stand on the size of the elite, $\theta$. Although this parameter affects the level of utility, it cancels out in our comparative welfare analysis due to logarithmic current-period utility. The baseline choices for the initial values of the state variables are as follows: the start level of the aggregate capital stock, $\widehat{K}_{0}$, is chosen to be 20 times below the steady-state level so that the average growth rate of the GDP is roughly $10.9 \%$ p.a. in the first 10 years and then $4.2 \%$ and $3.2 \%$ in the second and the third decade, respectively. Regarding the distribution, we assume the elite's share in the initial capital stock, $\left(1-\kappa_{0}\right)$, to be 0.8 . We will, however, perform additional simulations for different combinations of initial conditions.

Note that the choices for $\alpha$ and $\rho$ represent values routinely used in growth theory. The remaining numbers are chosen to broadly capture the situation in Porfirian Mexico (18771911) which can be viewed as a model case for the present framework. Regarding annual productivity growth, Razo and Haber (1998) report numbers in the range of 2-3\%. Data from Maddison (2007) implies further that the average yearly GDP per capita growth rate in the third decade of the Porfirian era was approximately 3.2\% (earlier data is scarce). Finally, although there is hardly evidence on the initial distribution of capital, Haber (1989, Chap. 3) suggests that $\left(1-\kappa_{0}\right)=0.8$ might be a reasonable choice (while, to mention it only for completeness, $\theta$ is estimated to be just $1 \%$ of the population) ${ }^{25}$ Given this parametrization, the steady-state level of capital, $\widehat{K}_{f b}^{*}$, is given by 11.04 while $\kappa_{f b}^{*}$ can be numerically computed as 0.75 .

Simulation results We assess the welfare implications for four different values of $\lambda<\kappa_{f b}^{*}$, namely for $0.5,0.4,0.3$, and 0.2 (and illustrate the associated behavior of some of the endogenous variables in Figs. 6, 7). Our findings are as follows: at the onset of the accumulation process, a representative oligarch would accept a downward shift of the entire path of productivity of at most $31 \%$ in order to have $\lambda=0.5$ rather than perfect enforcement; in order to have $\lambda$ equal to 0.4 or 0.3 , the elite would accept downward shifts of maximum 42 and $49 \%$, respectively; finally, if $\lambda=0.2$, the compensating shift would be $55 \%$. Clearly, these numbers suggest significant welfare implications: at early stages of development, the price-manipulation effect and the slowdown effect may be so strong that the oligarchs prefer to establish elite-protecting institutions even if they permanently slashed productivity and hence long-run output by half. Moreover, as argued above, these numbers represent just lower bounds if the elite is free to improve contract enforcement (and thus productivity) later on.

Note further that, in the present simulations, the impact of creditor protection is monotonic. Lower levels of $\lambda$ are consistently associated with "lower" trajectories of $\widehat{K}$ and $\kappa$ (see Fig. 6) but also with higher utility levels for the representative oligarch. So even though a lower $\lambda$ goes together with lower deposits and hence less scope for "cheap" external finance, there is (in a broad range) a clear negative link between creditor protection and the elite's welfare. ${ }^{26}$ Thus the slowdown effect appears to be the dominant component in the overall welfare effect.

Table 1 shows the corresponding numbers for different start values of $\widehat{K}_{0}$ and $\kappa_{0}$. The basic picture is that the welfare implications are substantial in each of the reported situations. Moreover, the table reveals two additional interesting patterns. First, the representative oligarch benefits stronger (i.e., is willing to accept even higher productivity losses in exchange for elite-protecting institutions) if the initial aggregate capital stock is lower. The reason

25 Note: (i) Razo and Haber (1998) numbers refer to productivity growth in the textile industry; (ii) the GDP
p.c. growth rate for the third decade is based on Maddison (2007) entries for the years 1895 and 1904; (iii) the
elite's share in aggregate capital is based on Haber's (1989, Chap. 3) remark that the elite, representing 1\% of
the population, owned the lion's share of national wealth (see Table 1 for other plausible values).
26 Note further that a large number of additional simulations have not led to any signs of non-monotonicity. 
(a) The aggregate capital stock over time

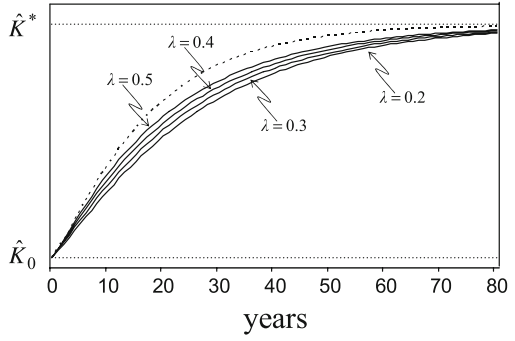

Note $:\left(\hat{K}_{0}, \kappa_{0}\right)=(0.5,0.2) ; \alpha=0.33, \rho=0.04, g=0.025$ (b) The distribution of the aggregate capital stock over time

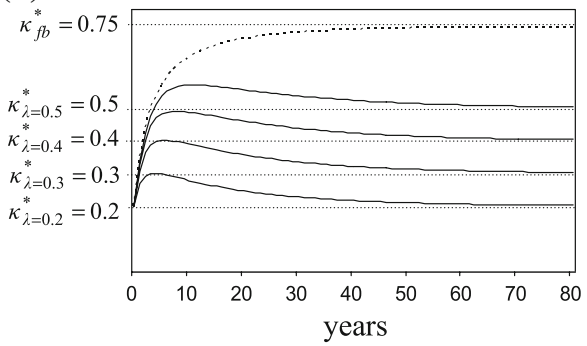

Fig. 6 Dynamics of the aggregate capital stock and its distribution with different $\lambda$ s (for a constant path of B)

(a) The aggregate output over time

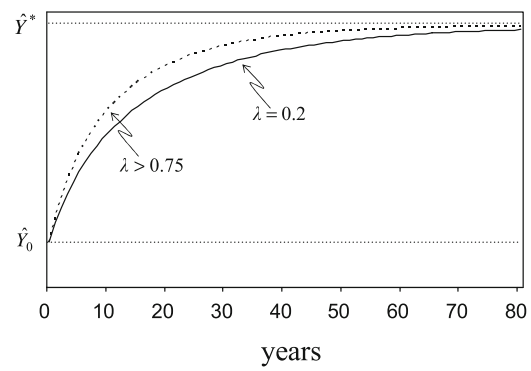

(b)

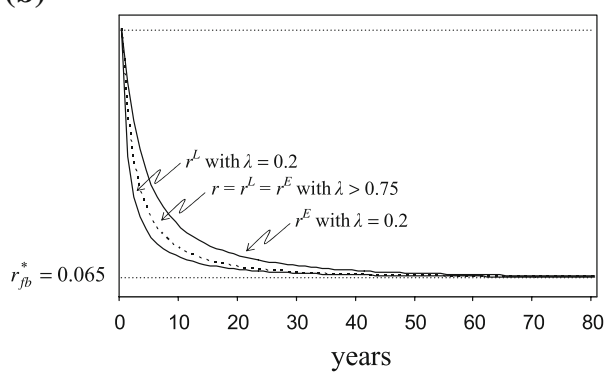

Note: $\left(\hat{K}_{0}, \kappa_{0}\right)=(0.5,0.2) ; \alpha=0.33, \rho=0.04, g=0.025$

Fig. 7 Dynamics of the aggregate output and the rates of return with different $\lambda$ s (for a constant path of B)

is that, at a lower level of accumulation, the oligarchs face a longer period during which they enjoy cheap access to highly productive capital. Second, the welfare gain increases in the workers' share in initial capital: with the elite owning less capital in relative terms, the borrowing rate has to fall farther below the marginal product, particularly at early stages of development. Thus, during this period, the rents per unit of capital borrowed are larger.

\subsection{Endogenous institutional change}

The aim of this final quantitative exercise is to provide an intuition for the length of the period during which elite-protecting institutions endogenously persist. More specifically, given a certain productivity-depressing impact of the elite-protecting environment, we determine the moment the elite finds it optimal to switch to perfect enforcement.

We continue to rely on the parameter choices and initial conditions introduced above and, for the most part, set $\underline{\lambda}$ equal to 0.2 (but briefly consider other values). Moreover, for convenience, the simulations are performed under the assumption that the decision on institutions is taken every 5 years, with the first decision in $t=0$. On this basis, our simulations predict the elite-protecting environment to persist for 55 years if the associated productivity differential is $10 \%$ (as compared to the first-best world with $\bar{\lambda}=1$ ). ${ }^{27}$ The corresponding number is

27 Formally, a productivity differential of $10 \%$ means $B_{t}(\underline{\lambda})=0.9 B_{t}(\bar{\lambda})$, whereas again $B_{t}(\lambda)=$ $A_{t}(\lambda)^{\alpha /(1-\alpha)}$. 


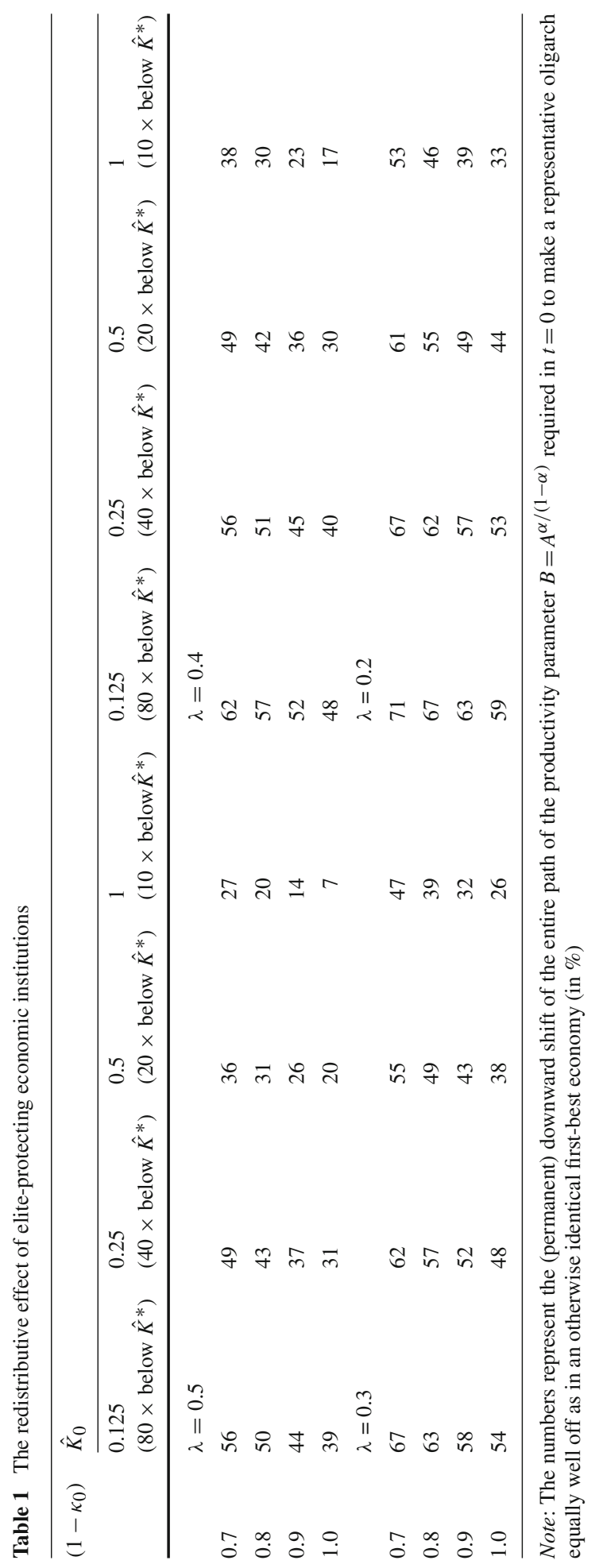


40 years in case of a productivity differential of 20\%; for losses of both 30 and $40 \%$ we get a period of 30 years; finally, if the differential were $50 \%$, the oligarchs would find it optimal to preserve elite-protecting institutions for two decades. Note further that these numbers are not particularly sensitive to the specific choice of $\underline{\lambda}$. For instance, with $\underline{\lambda}=0.3$ and a productivity loss of $30 \%$, the distortions would still persist for 30 years.

It is finally worth pointing out that these results only apply if improvements in contract enforcement are costless. Otherwise, if stronger contracting institutions came at a cost (as discussed in the previous section), the elite would switch at an even later stage. For the sake of illustration, assume that strong contracting institutions require a permanent consumption tax of $10 \%$ (while $\lambda_{t}=\underline{\lambda}$ is costless). Then, given a productivity differential of $30 \%$, the oligarchs would preserve the elite-protecting environment for 50 years.

In brief, relying on reasonable parameter choices, these final quantitative results again reflect the significance of the price-manipulation and slowdown effects at early stages of development: in exchange for cheap access to credit and a slower pace of aggregate accumulation, the model predicts the elite to accept substantial productivity losses over considerable periods of time.

\section{Summary and conclusions}

Economic institutions give often rise to substantial inequality in the access to economic opportunities, most notably in low-income countries. Incumbent producers tend to be protected from outside competitors as a result of administrative barriers to entry or due to poor contracting institutions which reduce the availability of credit (and other inputs) for prospective entrepreneurs. This paper introduces such elite-protecting institutions into the infinite-horizon framework in order to address two related sets of issues: first, how and through which channels do these distortions affect economic development and the evolution of the wealth distribution? Second, adopting a political-economy perspective, what can the consequences of elite-protecting institutions teach us about their high incidence among poor countries?

We find the implications of such institutions to be especially rich in less-advanced economies. In particular, if capital is scarce, elite-protecting institutions exert a major impact on the dynamics of the distribution. While a similar undistorted economy would grow more equal over time, elite-protecting institutions ensure that the aggregate capital stock remains or becomes even more concentrated in the hands of a tiny group. The reason is a price-manipulation effect: the workers have to accept relatively low deposit rates and so save only little. To the oligarchs, however, low deposit rates mean cheap access to credit and hence high profits. As a result, they accumulate fast so that the wealth distribution gets polarized. Moreover, due to the strong distortion of the workers' savings incentives, the aggregate capital stock grows at a lower rate. This slowdown effect is a second channel through which elite-protecting institutions benefit the oligarchs: slower aggregate accumulation means a slower decline in the marginal product of capital—which benefits the major capital owners.

There are, however, also negative consequences for the elite. In particular, weak contract enforcement may limit the oligarchs' access to other crucial inputs and thus impair productivity. Interestingly, magnitude and direction of the net effect crucially depend on the level of development: at low levels, the beneficial effects outweigh even significant productivity differentials. Yet, with capital no longer scarce, the positive effects weaken so that the net effect turns negative at some point. Clearly, this shift in the cost-benefit ratio offers an explanation for why weak contracting institutions (and costly regulation of entry) are mainly adopted in less-advanced economies: at early stages of development, a powerful group has 
strong incentives to push for such distortions - which then prevent the economy from advancing quickly by depressing productivity and aggregate savings. It is only at more advanced levels where all segments of society unanimously support strong contracting institutions.

The present analysis suggests that elite rule and capital scarcity are important forces behind the emergence of financial suppression and complementary barriers to entry. A brief survey of historical evidence from two well-studied countries-Mexico in the Porfirian era (1877-1911) and South Korea during the Park years (1961-1979)—broadly supports the mechanisms highlighted here. Yet, a more exhaustive analysis of institutional persistence and change in oligarchies will be an essential and interesting topic for future research.

\section{A Appendix}

Proof of Lemma 1 Suppose first that $\kappa$ never falls and never stays unchanged during the transition towards the steady state. Then, the claim immediately follows.

Suppose now that $\kappa$ decreases or remains constant at least once. By aggregating Eq. (11) across oligarchs and remembering Eq. (13) we can calculate the oligarchs' share in aggregate consumption, $C_{t}^{E} / C_{t}$, as $\left(1-\kappa_{t}\right)\left(1+r_{t}\right) \widehat{K}_{t}\left(\left(1+r_{t}\right) \widehat{K}_{t}+\widehat{H}_{t}\right)^{-1}$. From the Euler equation we know that this ratio does not change over time since - in the first-best economy- the rate of return is the same for workers and oligarchs. In particular, $C_{t}^{E} / C_{t}$ takes the same value in the transition towards the steady state as in the steady state. Hence, using $1+r_{f b}^{*}=(1+\rho)(1+g)$ and $\widehat{H}_{f b}^{*}=(1+\rho) \rho^{-1} \widehat{w}_{f b}^{*}$, we get

$$
\frac{C_{t}^{E}}{C_{t}}=\left(1-\kappa_{t}\right) \frac{\left(1+r_{t}\right) \widehat{K}_{t}}{\left(1+r_{t}\right) \widehat{K}_{t}+\widehat{H}_{t}}=\left(1-\kappa_{f b}^{*}\right) \gamma,
$$

whereas $\gamma \equiv \alpha \rho(1+g) /(\rho+g(1+\rho-\alpha))$.

Suppose now that $\kappa_{t+1} \leq \kappa_{t}$ or, equivalently, that $1-\kappa_{t+1} \geq 1-\kappa_{t}$. Then, since

$$
\left(1-\kappa_{t+1}\right)=\left(1-\kappa_{t}\right) \frac{\left(1+r_{t}\right) \widehat{K}_{t}}{\left(1+r_{t}\right) \widehat{K}_{t}+(1+\rho) \widehat{w}_{t}-\rho \widehat{H}_{t}},
$$

we have $(1+\rho) \widehat{w}_{t}-\rho \widehat{H}_{t} \leq 0$ or, equivalently, $\widehat{H}_{t} \geq(1+\rho) \rho^{-1} \widehat{w}_{t}$. Using this inequality in Eq. (A-1) leaves us with

$$
\left(1-\kappa_{t}\right) \delta\left(\widehat{K}_{t}\right) \geq\left(1-\kappa_{f b}^{*}\right) \gamma
$$

whereas

$$
\delta\left(\widehat{K}_{t}\right)=\frac{1+\alpha \widehat{K}_{t}^{\alpha-1}}{1+\alpha \widehat{K}_{t}^{\alpha-1}+(1+\rho) \rho^{-1}(1-\alpha) \widehat{K}_{t}^{\alpha-1}} .
$$

Further, since $\widehat{H}_{f b}^{*}=(1+\rho) \rho^{-1} \widehat{w}_{f b}^{*}, \delta\left(\widehat{K}_{f b}^{*}\right)$ equals $\gamma$. Then, because $\delta^{\prime}\left(\widehat{K}_{t}\right)>0$ for $\widehat{K}_{t}<\widehat{K}_{f b}^{*}$, we have $\delta\left(\widehat{K}_{t}\right)<\gamma$ if $\widehat{K}_{t}<\widehat{K}_{f b}^{*}$. Hence,

$$
\left(1-\kappa_{t}\right)>\left(1-\kappa_{f b}^{*}\right) \text { or } \kappa_{f b}^{*}>\kappa_{t} .
$$

Finally, assume that $\kappa$ decreases (or remains constant) for the first time between $\tau \geq 0$ and $\tau+1$. Then, $\kappa_{f b}^{*}>\kappa_{\tau} \geq \kappa_{0}$.

Proof of Lemma 2 Suppose first that $\widehat{C}_{0}$ is strictly lower in the elite-protecting economy. According to Eq. (13), this can only be true if $\widehat{H}_{0}$ is strictly lower than in the first-best case. 
Then, since $\widehat{K}_{0}$ is exogenous, $\widehat{K}_{1}$ must be higher (Eq. 16). Accordingly, $r_{1}^{L}$ will be lower and $\widehat{w}_{1}$ will be higher (both in a strict sense) than in the first-best economy. Since $\widehat{w}_{0}$ is the same in both economies and $r_{1}^{L}$ is strictly lower with elite-protecting institutions, it follows from Eq. (15) that $\widehat{H}_{1}$ must be strictly lower (as compared to the first-best economy). Therefore, we may infer that $\widehat{K}_{2}$ is higher and, consequently, that $r_{2}^{L}\left(\widehat{w}_{2}\right)$ is lower (higher) than in the first-best economy. Very similar to the step before, it must then be that $\widehat{H}_{2}$ is strictly lower in the elite-protecting economy. We may now repeat these arguments ad infinitum and conclude that, under the premise made above, the capital stock in the elite-protecting economy must be strictly higher at all future dates $t>0$. Since a higher stock of capital is associated with a lower workers' rate of return and a higher wage rate, $\widehat{H}_{0}$ must be strictly higher as well (Eq. 14). But this contradicts our initial assumption.

Suppose now that $\widehat{C}_{0}$ does not differ from the corresponding value in the first-best economy, implying that also $\widehat{H}_{0}$ is the same in both situations. Suppose further that $\kappa_{0}<\lambda$. Then, the two economies must evolve parallel until $\kappa$ reaches $\lambda$. From Lemma 1 and the assumption $\kappa_{f b}^{*}>\lambda$ we know that $\kappa$ must cross the $\lambda$-threshold at some point. Suppose that this happens for the first time in $t=\tau$, i.e., $\kappa_{\tau}>\lambda$ and $\kappa_{t} \leq \lambda \forall t<\tau$. Again, it is important to note that before $\tau$ both $\widehat{H}$ and $\widehat{K}$ (as well as the workers' rate of return and the wage rate) do not differ from their first-best counterparts and this is even true for $\widehat{K}_{\tau}$. But since $r_{\tau}^{L}$ is strictly lower with elite-protecting institutions, $\widehat{H}$ is (for the first time) strictly lower in the elite-protecting economy in $\tau$. We can now use the same arguments as in the first part of the proof in order to end with the contradiction that $\widehat{H}_{0}$ must be strictly higher in the elite-protecting economy. In case of $\kappa_{0} \geq \lambda$ this second part of the proof can be carried out in a similar way.

Having led the assumption that $\widehat{C}_{0}$ is smaller (or the same) to a contradiction, we infer that $\widehat{C}_{0}$ is strictly higher in the elite-protecting economy. This, in turn, implies that $\widehat{K}_{1}$ is smaller.

Proof of Proposition 1 Suppose that-contrary to what is stated in the proposition-there exists a $\tau$ so that in $\tau+1$ the aggregate capital stock is for the first time strictly higher in the elite-protecting economy than in the first-best case. More formally, assume that $\widehat{K}_{\tau+1}$ is strictly higher and that $\widehat{K}_{t}$ is lower or equal for all $t \leq \tau$. Then, $r_{\tau+1}^{L}$ must be strictly smaller in the former case (Eq. 6). So, for $\widehat{K}_{\tau+1}$ to be strictly higher with elite-protecting institutions, $\widehat{H}_{\tau+1}$ must be strictly lower (Eq. $16^{\prime}$ ) such that, again, $\widehat{K}_{\tau+2}$ is strictly higher in the elite-protecting economy (Eq. 16). This, in turn, implies that $\widehat{H}_{\tau+2}$ is smaller which leads to a higher $\widehat{K}_{\tau+3}$, and so on. Hence, from $\tau+1$ onwards, the the workers' rate of return will be strictly lower (as compared to first-best) and the wage rate will be strictly higher. But this means that $\widehat{H}_{\tau+1}$ must be strictly higher (Eq. 14)—which is a contradiction.

The assumption that the capital stocks are equal at some points in time can be led to a contradiction in a similar way. Further, since the first-best economy monotonically converges to $\widehat{K}_{f b}^{*}$, we also have $\widehat{K}_{t}<\widehat{K}_{f b}^{*}, t \geq 0$, in the elite-protecting economy.

Proof of Proposition 3 Suppose first that $\kappa_{0}<\lambda$. By Lemma 2 and Eq. (13), both $\widehat{C}_{0}$ and $\widehat{H}_{0}$ must be strictly higher in the elite-protecting economy. Suppose now that $\kappa_{t} \leq \lambda$ for all $t \geq 0$. Then, along the lines of the proof of Lemma 2, it can be shown that $\widehat{K}_{t}$ will be smaller than in the first-best economy at all dates $t>0$. Consequently, for all $t>0, r_{t}^{L}\left(w_{t}\right)$ must be strictly higher (strictly lower) in the elite-protecting economy. But this translates into a smaller $\widehat{H}_{0}$ (Eq. 14) which contradicts Lemma 2 . Hence, $\kappa$ must pass $\lambda$ from below at some future date. Suppose now that $\kappa$ reaches (or falls below) $\lambda$ from above at some date $\tau+1$. From Lemma 1 we know that $\kappa_{f b}^{*}\left(\widehat{K}_{\tau}, \kappa_{\tau}\right)>\lambda$. Hence, by Lemma 2 and Eq. (13), both $\widehat{C}_{\tau}$ and $\widehat{H}_{\tau}$ must be strictly higher than in a first-best economy that starts with $\widehat{K}_{\tau}$ and $\kappa_{\tau}$. Then, using the 
same arguments as above, $\kappa$ must pass $\lambda$ from below at some later date again. From this, $\kappa_{f b}^{*}\left(\widehat{K}_{t}, \kappa_{t}\right)>\lambda, t>0$, immediately follows.

Proof of Lemma 3 To see that aggregate savings are strictly positive in $t=0$, assume, to the contrary, that $\widehat{K}_{1} \leq \widehat{K}_{0}$. Since $\widehat{K}_{1}^{E}>\widehat{K}_{0}^{E}$, we have $\widehat{K}_{1}^{L}<\widehat{K}_{0}^{L}$ and therefore $\kappa_{1}<\kappa_{0}$, implying $1+r_{1}^{L}>1+r_{0}^{L} \geq 1+r_{f b}^{*}$. Hence, due to the Euler equation, $\widehat{C}^{L}$ must rise between the dates 0 and 1. Likewise, we have $\widehat{C}_{1}^{E}>\widehat{C}_{0}^{E}$ and therefore $\widehat{C}_{1}>\widehat{C}_{0}$. Then, by Eq. (13), $\widehat{H}_{1}>\widehat{H}_{0}$. Finally, it fallows from Eq. (16) that $\widehat{K}_{2}<\widehat{K}_{1} \leq \widehat{K}_{0}$. This sequence of steps can be repeated to see that $\widehat{K}^{L}$ will eventually reach zero. At that point, however, the workers can no longer follow the Euler equation since they may not borrow. Because such a path cannot be optimal, aggregate savings must be strictly positive in $t=0: \widehat{K}_{1}>\widehat{K}_{0}$.

Suppose now that $\widehat{K}_{t}>\widehat{K}_{t-1}$ and $\widehat{K}_{t+1} \leq \widehat{K}_{t}$ with $t>0$. Using the same arguments as above, we have $r_{t+1}^{L}>r_{t}^{L}$. Then, by Eq. $\left(16^{\prime}\right), \widehat{H}_{t+1}>\widehat{H}_{t}$. Further, Eq. (16) implies that $\widehat{K}_{t+2}<\widehat{K}_{t+1} \leq \widehat{K}_{t}$. But then, $r_{t+2}^{L}$ must be strictly higher than $r_{t+1}^{L}$ and, according to Eq. (15), $\widehat{H}$ must rise again between $t+1$ and $t+2$ so that $\widehat{K}_{t+3}<\widehat{K}_{t+2}$, and so on. Again, such a path cannot be optimal, and we conclude that $\widehat{K}_{t+1}>\widehat{K}_{t}, t \geq 0$.

Proof of Proposition 6 By the Bolzano-Weierstrass Theorem, the sequence $\left\{\kappa_{t}\right\}_{t \geq 0}$ has a convergent subsequence. We start the proof by showing that any convergent subsequence of $\left\{\kappa_{t}\right\}_{t \geq 0}$ has to converge to $\lambda$. Notice first that one can rule out that a subsequence converges to a value on the interval $(\lambda, 1]$ based on the same argumentation as in the text: the oligarchs' capital stock would grow towards infinity. Suppose now that there exists a subsequence $\left\{\kappa_{t_{j}}\right\}_{j \geq 0}$ that converges to a value on the interval $[0, \lambda)$, i.e., suppose without loss of generality that $\lim _{j \rightarrow \infty} \kappa_{t_{j}}=\lambda-\varsigma$ with $\varsigma>0$. Then, there must be a $\eta \in(0, \varsigma)$ so that there exists a $\tilde{j}$ with $\left|\lambda-\kappa_{t_{j}}\right|>\eta$ for all $j \geq \tilde{j}$. Consequently, by Proposition 3 , we know that $\kappa$ has to increase infinitely often by an amount larger than $\eta>0$ so that, since both $\widehat{K}^{E}$ and $\widehat{K}$ monotonically rise over time, $\widehat{K}$ must grow towards infinity. But this contradicts Proposition 5. We conclude that any convergent subsequence of $\left\{\kappa_{t}\right\}_{t \geq 0}$ converges to $\lambda$.

Suppose now that the sequence $\left\{\kappa_{t}\right\}_{t \geq 0}$ does not converge to $\lambda$. Then, there must be a $\varepsilon>0$ so that for all $t$ there exists a $m(t) \geq t$ with $\left|\lambda-\kappa_{m(t)}\right| \geq \varepsilon$. Consider the sequence $\left\{\kappa_{m(t)}\right\}_{t \geq 0}$. This sequence is also contained in the closed and bounded interval [0,1], and hence must have a convergent subsequence. This convergent subsequence, since it is also a subsequence of $\left\{\kappa_{t}\right\}_{t \geq 0}$, must converge to $\lambda$. But this contradicts the inequality $\left|\lambda-\kappa_{m(t)}\right| \geq$ $\varepsilon$. Therefore, we have $\lim _{t \rightarrow \infty} \kappa_{t}=\lambda$.

Solution to the decision problem in Sect. 4 The set of first-order conditions reads

$$
\begin{gathered}
(1-\gamma) p_{t} z_{i t}^{\gamma} q_{i t}^{-\gamma}-R_{t}-\mu_{1 t}\left((1-\gamma) \lambda p_{t} z_{i t}^{\gamma} q_{i t}^{-\gamma}-R_{t}\right)-\mu_{2 t}\left((1-\gamma) \lambda p_{t} z_{i t}^{\gamma} q_{i t}^{-\gamma}\right)=0 \\
\gamma p_{t} z_{i t}^{\gamma-1} q_{i t}^{1-\gamma}-p_{t} \chi-\mu_{1 t}\left(\gamma \lambda p_{t} z_{i t}^{\gamma-1} q_{i t}^{1-\gamma}-\lambda p_{t} \chi\right)-\mu_{2 t}\left(\gamma \lambda p_{t} z_{i t}^{\gamma-1} q_{i t}^{1-\gamma}-p_{t} \chi\right)=0 \\
\mu_{1 t}\left(\lambda p_{t}\left(z_{i t}^{\gamma} q_{i t}^{1-\gamma}-\chi z_{i t}\right)-R_{t}\left(q_{i t}-k_{i t}\right)\right)=0 \text { and } \mu_{2 t}\left(\lambda p_{t} z_{i t}^{\gamma} q_{i t}^{1-\gamma}-p_{t} \chi z_{i t}\right)=0,
\end{gathered}
$$

with $\mu_{1 t} \leq 0$ and $\mu_{2 t} \leq 0$. A solution to this system includes the optimal values of the two endogenous variables in each of the four possible sub-cases which are associated with the relevance of the two restrictions in equilibrium (binding or not binding). Moreover, 
the solution states the conditions determining which of the four sub-cases is actually the relevant one.

Suppose first that the credit-restriction is binding and assume for the moment the technology restriction binds as well (Case $\left.\mu_{1 t}<0, \mu_{2 t}<0\right)$. Then, we get

$$
\widetilde{A}_{i t}=\widetilde{A}=(\lambda / \chi)^{\gamma /(1-\gamma)} \text { and } q_{i t}=\left(1-\left(\lambda p_{t} A(\lambda) / R_{t}\right)\right)^{-1} k_{i t},
$$

whereas $A(\lambda)=\widetilde{A}(1-\lambda)$. To determine the conditions under which this equilibrium is relevant, multiply Eq. (A-2) by $q_{i t}$ and Eq. (A-3) by $z_{i t}$ and then add the two expressions together. The result is $p_{t} A(\lambda)-R_{t}=\mu_{1 t}\left(\lambda p_{t} A(\lambda)-R_{t}\right)$ which immediately implies $p_{t} A(\lambda)>R_{t}>$ $\lambda p_{t} A(\lambda)$ since $\mu_{1 t}<0$. Further, Eq. (A-3) can only hold if $\lambda<\gamma$. Notice that the situation with only the credit-restriction binding (Case $\mu_{1 t}<0, \mu_{2 t}=0$ ) is very similar. In particular, the expression for $q_{i t}$ is unchanged, and we must also have $p_{t} A(\lambda)>R_{t}>\lambda p_{t} A(\lambda)$. The difference is that we now get $\widetilde{A}_{i t}=\widetilde{A}=(\gamma / \chi)^{\gamma /(1-\gamma)}$ and hence $A(\lambda)=\widetilde{A}(1-\gamma)$. Moreover, Eq. (A-3) can only be satisfied if $\lambda \geq \gamma$.

Consider now the cases in which the credit-restriction is not binding (Cases $\mu_{1 t}=0$, $\mu_{2 t}<0$ and $\left.\mu_{1 t}=0, \mu_{2 t}=0\right)$. A similar approach as above shows that these cases can only be relevant if $p_{t} A(\lambda)=R_{t}$. Moreover, we have again $\widetilde{A}_{i t}=\widetilde{A}=(\lambda / \chi)^{\gamma /(1-\gamma)}$ (and hence $A(\lambda)=\widetilde{A}(1-\lambda))$ if $\lambda<\gamma$ and $\widetilde{A}_{i t}=\widetilde{A}=(\gamma / \chi)^{\gamma /(1-\gamma)}$ (and hence $A(\lambda)=\widetilde{A}(1-\gamma)$ ) if $\lambda \geq \gamma$. Finally, $q_{i t}$ can take any value on the interval $\left[k_{i t},(1-\lambda)^{-1} k_{i t}\right]$.

Proof of Proposition 7 Note first that the sequences $\left\{K_{t}\right\}_{t \geq 0},\left\{\kappa_{t}\right\}_{t \geq 0}$ and $\left\{\lambda_{t}\right\}_{t \geq 0}$-together with the sequence of the workers' belief about the future evolution of $K, \kappa$, and $\lambda-$ constitute a politico-economic equilibrium if, at each point in time, they are consistent with (i) the aggregated individual consumption-savings behavior (which, in turn, is based on the beliefs about the future evolution of the sequences in case of the workers) and (ii) the optimal institutional choice by the elite.

We now start the proof by introducing some notation: we denote by $\widehat{K}_{t, \underline{\lambda}}$ and $\kappa_{t, \underline{\lambda}}$ the values of the two state variable as long as enforcement is weak. Then, relying on this notation (and provided that indeed $\lambda_{t}=\underline{\lambda}$ ), the representative oligarch's capital stock in period $t$ can be written as $\left(1-\kappa_{t, \underline{\lambda}}\right) K_{t, \underline{\lambda}} /(1-\theta)$, where $K_{t, \underline{\lambda}} \equiv \widehat{K}_{t, \underline{\lambda}} B_{t}(\underline{\lambda})$. Thus, under these circumstances, the oligarch's end-of-period wealth is denoted by

$$
a_{t, \underline{\lambda}} \equiv\left(1+r^{E}\left(\widehat{K}_{t, \underline{\lambda}}, \kappa_{t, \underline{\lambda}}\right)\right)\left(1-\kappa_{t, \underline{\lambda}}\right) K_{t, \underline{\lambda}} /(1-\theta),
$$

where the rate of return $r^{E}\left(\widehat{K}_{t, \underline{\lambda}}, \kappa_{t, \underline{\lambda}}\right)$ is given in Eq. (7).

Remember now that, as long as the elite sticks with weak enforcement, the two state variables behave as if $\underline{\lambda}$ were in place forever even if there is a switch to perfect enforcement in the future. Hence, the dynamics of $\widehat{K}_{t, \underline{\lambda}}$ and $\kappa_{t, \underline{\lambda}}$ continues to be given by Propositions 5 and 6, respectively. In particular, $\widehat{K}_{t, \underline{\lambda}}$ and $\kappa_{t, \underline{\lambda}}$ converge to the steady state levels $\widehat{K}_{f b}^{*}$ and $\underline{\lambda}$ as indicated in the propositions. As a result, we can infer that $a_{t, \underline{\lambda}}$ converges to

$$
a_{t, \underline{\lambda}}^{*} \equiv\left(1+\alpha\left(\widehat{K}_{f b}^{*}\right)^{\alpha-1}\right)(1-\underline{\lambda}) K_{t, \underline{\lambda}} /(1-\theta) .
$$

We now continue by showing that—given the paths of $\widehat{K}_{t, \underline{\lambda}}, \kappa_{t, \underline{\lambda}}$ and $a_{t, \underline{\lambda}}$ - switching to $\bar{\lambda}$ must become optimal at some point $t \geq 1$ in the future. To this end, we define the variable

$$
\tilde{a}_{t, \underline{\lambda}} \equiv\left(1+\alpha\left(\frac{K_{t, \underline{\lambda}}}{B_{t}(\overline{\bar{\lambda}})}\right)^{\alpha-1}\right)\left(1-\kappa_{t, \underline{\lambda}}\right) K_{t, \underline{\lambda}} /(1-\theta),
$$


which gives the representative oligarch's wealth if, in a given period $t$, the elite switches from $\underline{\lambda}$ to $\bar{\lambda}$. To proceed further, note that the "deviation wealth" $\widetilde{a}_{t, \underline{\lambda}}$ converges to

$$
\widetilde{a}_{t, \underline{\lambda}}^{*} \equiv\left(1+\alpha\left(\widehat{K}_{f b}^{*}\right)^{\alpha-1}\left(\frac{B_{t}(\bar{\lambda})}{B_{t}(\underline{\lambda})}\right)^{1-\alpha}\right)(1-\underline{\lambda}) K_{t, \underline{\lambda}} /(1-\theta) .
$$

Looking at Eqs. (A-4) and (A-5) now reveals that $\tilde{a}_{t, \underline{\lambda}}^{*}>a_{t, \underline{\lambda}}^{*}$ since $B_{t}(\bar{\lambda}) / B_{t}(\underline{\lambda})>1$. So there must exist a $\tau$ such that $\tilde{a}_{\tau, \underline{\lambda}}>a_{t, \underline{\lambda}}$ for all $t \geq \tau$. But this means that opting for $\lambda_{\tau}=\bar{\lambda}$ is welfare-improving from the perspective of the oligarchs: after the switch, the laws of the first-best economy apply, and the economy converges to the ("higher") balanced growth path associated with $B_{t}(\bar{\lambda})$. During this transition, the oligarchs' wealth (denote it by $a_{t, \bar{\lambda}}$ ) steadily improves over $\widetilde{a}_{\tau, \underline{\lambda}}$. As a result, we have $a_{t, \bar{\lambda}}>a_{t, \underline{\lambda}}$ for all $t>\tau$. The final step is now to see that an oligarch's consumption level is proportional to his wealth - which implies that switching to $\bar{\lambda}$ in $\tau$ leads to strictly higher consumption from this period onwards.

Open Access This article is distributed under the terms of the Creative Commons Attribution Noncommercial License which permits any noncommercial use, distribution, and reproduction in any medium, provided the original author(s) and source are credited.

\section{References}

Acemoglu, D. (2008). Oligarchic versus democratic societies. Journal of the European Economic Association, 6(1), 1-44.

Acemoglu, D., Antràs, P., \& Helpman, E. (2007). Contracts and technology adoption. American Economic Review, 97(3), 916-943.

Acemoglu, D., Johnson, S., \& Robinson, J. A. (2001). The colonial origins of comparative development: An empirical investigation. American Economic Review, 91(5), 1369-1401.

Acemoglu, D., \& Verdier, T. (1998). Property rights, corruption and the allocation of talent: A general equilibrium approach. Economic Journal, 108, 1381-1403.

Aghion, P., Banerjee, A., \& Piketty, T. (1999). Dualism and macroeconomic volatility. Quarterly Journal of Economics, 114(4), 1359-1397.

Aghion, P., \& Bolton, P. (1997). A theory of trickle-down growth and development. Review of Economic Studies, 64(2), 151-172.

Aghion, P., Howitt, P., \& Mayer-Foulkes, D. (2005). The effect of financial development on convergence: Theory and evidence. Quarterly Journal of Economics, 120(1), 173-222.

Antràs, P., \& Helpman, E. (2004). Global sourcing. Journal of Political Economy, 112(3), 552-580.

Banerjee, A., \& Duflo, E. (2005). Growth theory through the lens of development economics. In P. Aghion \& S. Durlauf (Eds.), Handbook of economic growth. Amsterdam: Elsevier.

Banerjee, A., \& Newman, A. (1991). Risk-bearing and the theory of income distribution. Review of Economic Studies, 58(1), 211-235.

Banerjee, A., \& Newman, A. (1993). Occupational choice and the process of development. Journal of Political Economy, 101(2), 274-298.

Beck, T., Demirgüç-Kunt, A., \& Levine, R. (2003). Law, endowments, and finance. Journal of Financial Economics, 70(2), 137-181.

Bénabou, R. (1996). Inequality and growth. In B. Bernanke \& J. Rotemberg (Eds.), NBER macroeconomics annual 1996. Cambridge: MIT Press.

Bertola, G., Föllmi, R., \& Zweimüller, J. (2006). Distribution in macroeconomic models. Princeton: Princeton University Press.

Braguinsky, S., \& Myerson, R. B. (2007). Capital and growth with oligarchic property rights. Review of Economic Dynamics, 10(4), 676-704.

Caselli, F., \& Gennaioli, N. (2006). Dynastic management. CEP Discussion Paper No 741, LSE.

Chang, S.-J. (2003). Financial crisis and transformation of Korean business groups. Cambridge: Cambridge University Press. 
Chatterjee, S. (1994). Transitional dynamics and the distribution of wealth in a neoclassical growth model. Journal of Public Economics, 54(1), 97-119.

Coatsworth, J. (1978). Obstacles to economic growth in nineteenth-century Mexico. American Historical Review, 83(1), 80-100.

Djankov, S., La Porta, R., Lopez-de Silanes, F., \& Shleifer, A. (2002). The regulation of entry. Quarterly Journal of Economics, 117(1), 1-37.

Djankov, S., McLiesh, C., \& Shleifer, A. (2005). Private credit in 129 countries. Mimeo: Harvard University.

Engerman, S., \& Sokoloff, K. (1997). Factor endowments, institutions, and differential path of growth among new world economies: A view from economic historians of the United States. In H. Stephen (Ed.), How Latin America fell behind. Stanford, CA: Stanford University Press.

Erosa, A., \& Hidalgo Cabrillana, A. (2008). On finance as a theory of TFP, cross-industry productivity differences, and economic rents. International Economic Review, 49(2), 437-473.

Galor, O., \& Moav, O. (2004). From physical to human capital accumulation: Inequality and the process of development. Review of Economic Studies, 71(4), 1001-1026.

Galor, O., \& Moav, O. (2006). Das human-kapital: A theory of the demise of the class structure. Review of Economic Studies, 73(1), 85-117.

Galor, O., Moav, O., \& Vollrath, D. (2009). Inequality in landownership, the emergence of human-capital promoting institutions, and the great divergence. Review of Economic Studies, 76(1), 143-179.

Galor, O., \& Zeira, J. (1993). Income distribution and macroeconomics. Review of Economic Studies, 60(1), 35-52.

Haber, S. (1989). Industry and underdevelopment: The industrialization of Mexico, 1890-1940. Stanford: Stanford University Press.

Haber, S. (1991). Industrial concentration and the capital markets: A comparative study of Brazil, Mexico, and the United States, 1830-1930. Journal of Economic History, 51(3), 559-580.

Haber, S., Razo, A., \& Maurer, N. (2003). The politics of property rights. Cambridge: Cambridge University Press.

Hadi, A. (1992). Identifying multiple outliers in multivariate data. Journal of the Royal Statistical Society $B, 54(3), 761-771$.

Hall, R., \& Jones, C. (1999). Why do some countries produce so much more output per worker than others?. Quarterly Journal of Economics, 114(1), 83-116.

Kaldor, N. (1956). Alternative theories of distribution. Review of Economic Studies, 23(2), 83-100.

Kang, D. (2002a). Crony capitalism: Corruption and development in South Korea and the Philippines. Cambridge: Cambridge University Press.

Kang, D. (2002b). Bad loans to good friends: Money, politics, and the developmental state in South Korea. International Organizations, 56(1), 177-207.

Krusell, P., \& Ríos-Rull, J.-V. (1996). Vested interests in a positive theory of stagnation and growth. Review of Economic Studies, 63(2), 301-329.

Kuznets, S. (1955). Economic growth and income inequality. American Economic Review, 45(1), 1-28.

Maddison A. (2007). World population, GDP and Per Capita GDP, 1-2003 AD, Data set available on http://www.ggdc.net/maddison/.

Matsuyama, K. (2000). Endogenous inequality. Review of Economic Studies, 67(4), 743-759.

Matsuyama, K. (2006). The 2005 Lawrence R. Klein lecture: Emergent class structure. International Economic Review, 47(2), 327-360.

Maurer, N. (2002). The power and the money: The Mexican financial system 1876-1932. Stanford: Stanford University Press.

Mookherjee, D., \& Ray, D. (2002). Is inequality stable? American Economic Review, 92(2), $253-259$.

Mookherjee, D., \& Ray, D. (2003). Persistent inequality. Review of Economic Studies, 70(2), 369-393.

Piketty, T. (1997). The dynamics of the wealth distribution and the interest rate with credit rationing. Review of Economic Studies, 64(2), 173-189.

Rajan, R., \& Zingales, L. (2003). The great reversals: The politics of financial development in the twentieth century. Journal of Financial Economics, 69(1), 5-50.

Razo, A., \& Haber, S. (1998). The rate of growth of productivity in Mexico, 1850-1933: Evidence from the cotton textile industry. Journal of Latin American Studies, 30(3), 481-517.

Rose-Ackerman, S. (1999). Corruption and government: Causes, consequences, and reform. New York: Cambridge University Press.

Treisman, D. (1995). The politics of soft credit in post-Soviet Russia. Europa-Asia Studies, 47(6), 949-976. 